\title{
Arousal-biased competition in perception and memory
}

\author{
Mara Mather and Matthew R. Sutherland \\ University of Southern California
}

\begin{abstract}
Our everyday surroundings besiege us with information. The battle is for a share of our limited attention and memory, with the brain selecting the winners and discarding the losers. Previous research shows that both bottom-up and top-down factors bias competition in favor of high priority stimuli. We propose that arousal during an event increases this bias both in perception and in long-term memory of the event. Arousal-biased competition theory provides specific predictions about when arousal will enhance and when it will impair memory for events, accounting for some puzzling contradictions in the emotional memory literature.
\end{abstract}

"Selection is the very keel on which our mental ship is built. And in this case of memory its utility is obvious. If we remembered everything, we should on most occasions be as ill off as if we remembered nothing." William James, The Principles of Psychology, p. 680.

The brain's ability to prioritize information allows us to think and take action without being overwhelmed by external stimuli or internal thoughts and feelings. Attending to what is important while ignoring extraneous detail can enhance performance in challenging situations, such as when facing a difficult task or a threat to one's safety. A wide range of cognitive and emotional challenges increase autonomic arousal, affecting heart rate, galvanic skin response, and pupil dilation. Even something as simple as an emotional picture shown for a few seconds can increase autonomic arousal (e.g., Bradley, Miccoli, Escrig, \& Lang, 2008). Emotional stimuli and cognitive challenges also increase levels of stress hormones such as epinephrine and cortisol.

Given the importance of focused attention in challenging situations, it would be helpful if arousal increased how selective the brain is when processing information. Many studies have examined the role of arousal in the selectivity of information processing, eliciting arousal in a variety of ways, including via emotional stimuli, stress, and administration of stress hormones. Some prominent characterizations of how arousal affects the selectivity of memory are listed in Table 1 . These arousal effects on memory are diverse and no previous theory we are aware of can account for them all. Furthermore, even at the specific level, each separate arousal effect characterization (such as "arousal induces retrograde amnesia") faces contradictory findings in the literature (see right-hand column in Table 1). In this paper, we propose a new theory of arousal-biased competition to account for how arousal affects memory selectivity. We start by outlining the theory and how it operates in perception. Then we turn to the domain of memory to explain how the theory accounts for the eclectic and apparently contradictory findings outlined in Table 1.

Correspondence concerning this article should be addressed to Mara Mather, 3715 McClintock Ave, University of Southern California, Los Angeles, CA 90089. Electronic mail may be sent to mara.mather@usc.edu. 


\section{Arousal-Biased Competition}

What we call arousal-biased competition (ABC) is the notion that arousal (whether elicited by external stimuli, internal thoughts or stress hormones) modulates the strength of competing mental representations, enhancing memory for items that dominate the contest for selective attention. This competition for representation begins during perception and continues into long-term consolidation. During perception, arousal biases competition in favor of perceptually conspicuous or goal-relevant stimuli. Arousal then enhances memory consolidation for the most conspicuous or goal-relevant stimuli - regardless of whether those stimuli were arousing or not. ABC theory builds on existing biased-competition models of attention that we describe in the next section.

\section{Biased Competition in Non-Arousing Situations}

Imagine scanning a crowd of faces to find a friend. How can you find a specific face? Both bottom-up cues from the scene (such as a hand waving) and top-down goals (such as finding a friend with blonde hair) can bias attention towards particular faces, increasing the processing resources devoted to that face (Beck \& Kastner, 2009). Once the friend's face is located, another challenge is to maintain that face's representation and relative location despite potential distraction from the rest of the scene. In this section we review research on selective attention and biased competition in non-arousing situations.

One intuitive metaphor of selective attention is that of a spotlight, in which attention is focused on one region of the visual field, with stimuli outside that region having little influence (Posner, Snyder, \& Davidson, 1980). However, there are many ways in which selective attention does not conform to this metaphor (Cave \& Bichot, 1999). For instance, the set of features targeted for selective attention cannot always be defined based on feature locations. Instead, attention is often object-based (for a review see Scholl, 2001). So, for instance, when two transparent objects overlap, attention may be directed to one object, impairing processing of the other object (e.g., O'Craven, Downing, \& Kanwisher, 1999; Valdes-Sosa, Cobo, \& Pinilla, 2000).

The biased-competition theory of attention accounts for these object-based effects by assuming that objects in the visual field compete for neural representation (Bundesen, Habekost, \& Kyllingsbaek, 2005; Bundesen, 1990; Desimone \& Duncan, 1995; Desimone, 1998; Deco \& Rolls, 2005; Kastner \& Ungerleider, 2001; Miller \& Cohen, 2001). Biasedcompetition theory proposes three basic ideas (Beck \& Kastner, 2009; Duncan, 2006). First, the competitive nature of visual processing means that a stronger neural response to any one visual object comes at the expense of weaker responses to others. Second, top-down goals or signals bias competition. Third, competition is integrated across brain regions, so that a visual object that dominates in the visual cortex will likely dominate in other regions such as the prefrontal and parietal cortices.

Biased competition has been observed in single cell recordings from monkeys' inferotemporal cortex. This high-level visual area has neurons that selectively respond to complex object properties, contributing to object recognition. A single-cell recording study identified, for each recorded cell, a picture that produced a strong response (Picture A) and a picture that produced a weak or no response (Picture B; Chelazzi, Duncan, Miller, \& Desimone, 1998). When Picture A was shown alone, the cell increased its firing rate dramatically. However, when A and B were shown together, the cell initially showed a firing rate in between that seen for A and for B alone. By $300 \mathrm{~ms}$ later, the firing rate diverged for the 2-picture presentations depending on the monkey's current goal. If Picture A was the target, the firing rate for that cell rose to same rate as when only A was presented. 
If Picture B was the target, the firing rate decreased to the same rate as when only B was presented.

These data illustrate two important points. The first is that competition from Picture B interferes with the response to the preferred picture, as indicated by the lower initial response to Picture A in the 2-picture presentation than in the A-only presentation. The second important point is that the competition in the 2-picture presentation conditions is biased by top-down goals, so that more behaviorally relevant information wins the competition for representation.

Functional magnetic resonance imaging (fMRI) studies also reveal neural response patterns consistent with biased competition (e.g., Kastner, De Weerd, Desimone, \& Ungerleider, 1998; Reddy, Kanwisher, \& VanRullen, 2009). As in the single-cell recording studies (Chelazzi, et al., 1998; Chelazzi, Miller, Duncan, \& Desimone, 2001), directing attention to one of multiple objects reduces the suppressive effects of the competing objects, bringing activation closer to levels seen with just one object presented alone (Kastner, et al., 1998). During directed attention, a frontoparietal attentional network (including the anterior cingulate cortex) generates top-down biasing signals that modulate activity in sensory regions (Dehaene, Kerszberg, \& Changeux, 1998; Hampshire, Duncan, \& Owen, 2007; Hon, Epstein, Owen, \& Duncan, 2006; Hung, Driver, \& Walsh, 2005; Miller \& Cohen, 2001).

Competition for mental representation continues after stimuli disappear. For instance, in one study, participants saw a face and a scene next to each other on the screen (Johnson \& Johnson, 2009a). After the pictures disappeared, participants were cued to think about one of the two pictures. Compared to a control condition in which they were not asked to refresh either picture, thinking about the scene increased activity in the parahippocampal place area, a scene-selective area, whereas thinking about the face suppressed activity in the parahippocampal place area (see also Mitchell, Johnson, Higgins, \& Johnson, 2010). Thus, top-down goals bias competition among mental representations even when there are no external perceptual stimuli.

The selectivity supported by biased competition should be particularly important during stressful or threatening situations, when distractions may be dangerous. Indeed, a number of studies provide evidence that the arousal from stress or a threat biases competition in perception and attention. However, before turning to the evidence for arousal-biased competition, we first discuss "priority," a key concept for our theory.

\section{Routes to Stimuli Priority}

From the perspective of arousal-biased competition, whether arousal will enhance or impair perception of a particular item depends on that item's priority. Arousal amplifies the effects of competition, improving perception of high priority information and weakening perception of low priority information. This leads to the question of what determines priority. As described below, bottom-up sensory influences (the waving hand in the crowd) and topdown cognitive factors such as goal relevance and expectations (the search for a blondhaired friend) can independently determine priority (for a review see Fecteau \& Munoz, 2006). Other factors that predict priority, such as unexpectedness, emotional relevance and social relevance, reflect interactions of sensory and cognitive signals.

\section{Bottom-Up}

The bottom-up route to priority is via perceptual contrast. Targets in an array "pop out" when they differ from their context, whether that difference is in orientation, motion, luminance or color (Nothdurft, 2000). Using this fundamental rule about what draws 
attention, computational models can predict where eye fixations will land on an image by analyzing the image's center-surround contrast at every location (Berg, Boehnke, Marino, Munoz, \& Itti, 2009; Itti \& Koch, 2000). In these salience map models, the center-surround contrast is computed for a variety of different features (e.g., color, intensity, orientation, flicker, and motion) at different spatial scales and all the separate estimates of within-feature contrast are assembled into a global saliency map. Similar contrast algorithms can predict attention to auditory stimuli (Kayser, Petkov, Lippert, \& Logothetis, 2005).

In these models, a center-surround differentiation process mimics properties of local cortical inhibition. When the contrast is high between the center and the surround, "activation" for the center is increased and activation for the surround is inhibited. The result of several iterations of this competitive process is that only a few locations on the feature maps remain active (Fig. 1A). However, if the image consists of a set of items with equal contrast (Fig. 1B), the center-surround competition process leads all peaks to inhibit each other suppressing the entire map.

Arousal-biased competition predicts that arousal will amplify the effects of contrast by boosting excitation for the highest contrast item and inhibition of the surrounding context, leading to an even sparser set of active locations in the saliency map than under nonarousing conditions. But those that do survive will have greater activation levels.

\section{Top-Down}

Priority is also determined by top-down factors such as goals, knowledge and expectations. In particular, stimuli that are relevant to current goals gain priority over irrelevant stimuli. Many theoretical models posit that goal-directed attention enhances and suppresses representations of stimuli during perception (for a review see Walther \& Koch, 2007). Consistent with such models, directing people to remember scenes and ignore faces while they look at pictures of each leads to above-baseline activity in the parahippocampal place area, a scene-selective brain region; directing them to ignore scenes and remember faces leads to below-baseline activity in the parahippocampal place area (Gazzaley, Cooney, McEvoy, Knight, \& D'Esposito, 2005). This reveals both top-down enhancement and suppression of mental representations of the perceived scenes. Furthermore, internal representations of previously perceived stimuli are also enhanced if goal-relevant and suppressed if goal-irrelevant (e.g., Johnson \& Johnson, 2009b). Arousal-biased competition predicts that arousal will increase priority for goal-relevant stimuli and decrease priority for goal-irrelevant stimuli.

\section{Surprise}

While perceptual contrast and goal relevance are independent factors, other predictors of priority are determined by interactions of bottom-up perception and top-down reflection. For instance, novel and unexpected stimuli are prioritized due to the mismatch between perceptual input and prior knowledge (Itti \& Baldi, 2009; Ranganath \& Rainer, 2003). Analogous to salience maps for perceptual contrast, a computational model can quantify how surprising each location on a feature map is by comparing beliefs about what is likely to be in that location before and after seeing the information (Baldi \& Itti, 2010).

\section{Emotional Relevance}

Emotional relevance is another contributor to priority that has bottom-up and top-down components. Many studies demonstrate that emotional stimuli stand out more than neutral stimuli. For instance, when a neutral and an arousing picture are simultaneously presented, one's eyes are more likely to first fixate on the arousing picture and then fixate more frequently on it (Knight, et al., 2007; LaBar, Mesulam, Gitelman, \& Weintraub, 2000; 
Rosler, et al., 2005). This bias favoring the arousing picture even occurs under direct instructions to ignore the arousing items (Nummenmaa, Hyona, \& Calvo, 2006). Viewing emotional stimuli also increases activity in visual brain areas associated with object recognition, such as fusiform and inferotemporal cortices (Sabatinelli, Flaisch, Bradley, Fitzsimmons, \& Lang, 2004; Taylor, Liberzon, \& Koeppe, 2000) and, in event-related brain potential studies, leads to an early posterior negativity (Schupp, Flaisch, Stockburger, \& Junghofer, 2006), suggesting prioritized visual processing of emotional stimuli. Similar results have been observed in other sensory systems: emotionally evocative sounds increase activity in auditory cortex (superior temporal gyrus; Zald \& Pardo, 2002) and tasting pleasant or aversive liquid solutions increases activity in taste cortex (fronto-opercular insula; O'Doherty, Rolls, Francis, Bowtell, \& McGlone, 2001).

Debate about why emotional stimuli have enhanced priority has yielded evidence for both bottom-up and top-down mechanisms. For instance, a study in which participants detected one emotional face in an array of neutral faces found that computationally modeled bottomup visual saliency (using the model shown in Fig. 1; Itti \& Koch, 2000) predicted face detection speed (Calvo \& Nummenmaa, 2008). A study examining event-related brain potentials in response to difficult-to-see faces reveals top-down influences (Lee, et al., 2010). When participants thought they saw an emotional face but were actually looking at a neutral face, activity in posterior visual regions showed the same type of enhanced activity seen during actual emotional face perception. Thus, due to a mixture of factors, including bottom-up perceptual contrast and top-down cognitive factors, emotional stimuli are likely to have high priority. Furthermore, arousal (evoked either by those same stimuli or by another source) should increase the competitive advantage of the emotional stimuli over lower priority stimuli.

\section{Social Relevance}

Finally, social relevance can also increase stimulus priority. When asked just to look at a visual scene that includes human faces, people frequently fixate on the eyes (Birmingham, Bischof, \& Kingstone, 2009a, 2009b) - a tendency that is not accounted for by computationally modeled bottom-up visual saliency (Itti \& Koch, 2000). People's default interest in the social information other people's eyes convey may be the mechanism underlying this type of priority (e.g., Birmingham, Bischof, \& Kingstone, 2008). Information-seeking goals may lead eyes to attract more attention than would be predicted from their perceptual contrast.

\section{Evidence for Arousal-Biased Competition in Perception}

In this section of this paper we focus on arousal-biased competition in perception, reviewing evidence that arousal amplifies the bottom-up salience and the top-down competitive advantage of high versus low priority stimuli. We discuss how arousal-biased competition can account for arousal effects in binocular rivalry and tracking multiple items, as well as the brain mechanisms of how arousal modulates top-down priority.

\section{Arousal-Biased Competition Amplifies Perceptual Contrast}

To test whether arousal increases the competitive advantage of high contrast (and therefore salient) over low contrast (and therefore less salient) stimuli, we played arousing or nonarousing sounds before briefly presenting a circular array of eight letters (Fig. 2; Sutherland $\&$ Mather, in preparation). Three of the letters were printed in high contrast dark grey on the white background, whereas the other five letters were printed in lower contrast grey. Participants then reported which letters they saw. 
As expected, participants were more likely to report high contrast letters than low contrast letters. More interesting, however, was that hearing an arousing sound before viewing the letters significantly increased reporting of high contrast letters and decreased reporting of low contrast letters. Thus, arousal amplified the competitive advantage of perceptually salient stimuli and the competitive disadvantage of less salient stimuli. In a second experiment, participants were randomly assigned to have a fixation interval between the arousing sound and the letter presentation that ranged from 750-3000 ms (a replication of the first experiment) or to have an interval that ranged from $4000-6000 \mathrm{~ms}$. In the shortinterval condition, the arousal-biased competition effect replicated, but there was no significant effect of arousal in the long-interval condition. Thus, for only a brief period after their presentation, arousing auditory stimuli bias competition in favor of high contrast visual stimuli.

In that study, higher and lower contrast stimuli competed for mental representation. However, if a low contrast stimulus is shown alone and is the target of attention, arousalbiased competition should increase its priority, as it is the most strongly activated stimulus in the display. Indeed, several studies indicate that presenting an arousing cue can make subsequent low contrast stimuli presented alone on the screen more easily perceived (Laretzaki, Plainis, Argyropoulos, Pallikaris, \& Bitsios, 2010; Padmala \& Pessoa, 2008; Phelps, Ling, \& Carrasco, 2006). For instance, when participants with low trait anxiety were told to anticipate receiving 1-3 electric shocks during a 2-min experiment block, they showed an earlier visual evoked response P100 when shown an 8 or $12 \%$ contrast grating (Laretzaki, et al., 2010). The P100 latency was speeded under shock anticipation for both gratings, but significantly more for the higher contrast (12\%) than for the lower contrast $(8 \%)$ one. Interestingly, participants with high trait anxiety did not show any significant effect of anticipating shock. Future studies are needed to see if they were already too aroused at baseline to see any further effect or whether they might have been more internally focused rather than task focused (they rated their alertness significantly lower than did the low-trait-anxiety participants). An fMRI study revealed that this type of arousal-enhanced perception of target items is associated with increased activation in areas V1-V4 of visual cortex (Padmala \& Pessoa, 2008). In this study, an auditory cue on each trial indicated whether or not the trial might involve a shock. Anticipating a shock enhanced detection of low-contrast gratings, an effect that was associated with greater activity in early visual cortex.

In a similar study (Phelps, et al., 2006), participants tried to identify whether one of four gratings was tilted to the left or to the right. The gratings were shown for only a brief period ( $40 \mathrm{~ms}$; see Fig. 3A). A cue appeared before the gratings; it consisted either of a fearful or a neutral face presented in one location or in all four potential grating locations (Fig. 3B). Of course, there was an effect of spatial cueing: showing just one face (either neutral or fearful) in the same location as the upcoming tilted grating increased accuracy. There was also an effect of emotion: When a fearful face, rather than a neutral face, was used to cue the relevant grating, participants could identify the tilt direction at lower levels of contrast, consistent with the studies reviewed above. ${ }^{i}$ But an additional intriguing aspect of this study

\footnotetext{
${ }^{\mathrm{i}}$ The studies just described used low spatial frequency contrast gratings (i.e., with wide stripes). However, a recent study suggests that arousal does not enhance detection of high-spatial-frequency contrast gratings (Bocanegra \& Zeelenberg, 2009b). In fact, exposure to fear faces impaired tilt direction discrimination of subsequent high-spatial-frequency contrast gratings while enhancing tilt detection for low-spatial-frequency gratings. The authors suggested that the differences stem from the amygdala having more projections to the magnocellular visual pathways than to the parvocellular visual pathways, leading emotion to create a trade-off between magnocellular and parvocellular pathway information. Magnocellular channels process movement, small differences in brightness and low spatial frequency information, whereas parvocellular channels process color, form and the fine details conveyed by high spatial frequencies (Livingstone \& Hubel, 1988). More work is needed to see if arousal generally enhances contrast within magnocellular pathways but not within parvocellular pathways or if there is some other factor driving the high- vs. low-frequency difference.
} 
was the finding that the emotional enhancement was greater when the cue consisted of just one face in the same location as the upcoming tilted grating than when the cue was four faces of the same type. Thus the effects of emotion and attention were not just independent effects, but interacted to enhance perception more than either effect on its own.

\section{Arousal-Biased Competition Amplifies the Effects of Goal Relevance}

Consistent with $\mathrm{ABC}$ theory, a study using event-related brain potential measures revealed that arousal amplifies the effect of goal relevance, especially during stimulus evaluation phases of processing (Schupp, et al., 2007). In this study, participants viewed a rapid slide show of pictures, which consisted of erotic pictures of people, neutral pictures of people and scenes of mutilation or injury. Participants were either asked to count the erotica, neutral people or mutilation pictures. This counting task manipulated which type of picture was the focus of attention. An ERP component thought to reflect the process of stimulus evaluation called the P3 (about 200-350 ms after stimulus onset) was more pronounced for each stimulus type when it was the focus of attention, but this attention effect was greater for the erotica and mutilation pictures than for the neutral pictures.

Of particular interest are studies that separate the arousal or stress-inducing stimulus from the competition for attention. These studies indicate that arousal enhances perception for the highest priority stimulus, and reduces perception for what has lower priority-even when the high priority stimuli are not themselves arousal inducing. For example, Hockey (1970b) had participants perform a central pursuit-tracking task, while also indicating whenever one of six lamps signaled. The lamps flanked both sides of the central tracking task display. Lamps closest to the display were considered 'central,' while lamps furthest from the display were considered 'peripheral.' Some participants heard constant loud noise (100 dB); whereas others heard less intense noise $(70 \mathrm{~dB})$. In the unequal condition, the central lamps were more likely to signal — and were therefore more goal-relevant— than the peripheral lamps. Performance in the two noise conditions did not differ across the central and peripheral lamps in the equal condition, but in the unequal condition, in which central lamps were more likely to signal, noise-induced arousal led to faster responses to the central lamps and slower responses to the peripheral lamps. In other words, the noise-induced arousal increased existing biases towards the goal-relevant lamps at the cost of the goal-irrelevant lamps but did not increase the bias towards spatially central cues when spatial layout was not linked with goal relevance (see also Hockey \& Hamilton, 1970).

$\mathrm{ABC}$ theory indicates that a central spatial location does not necessarily give a stimulus priority. Instead, goal relevance interacts with the perceptual features of competing stimuli to determine stimulus priority. Consistent with this idea, when arousal is manipulated via electric shock, aroused subjects show greater processing of goal-relevant but spatially peripheral cues than do control subjects (Cornsweet, 1969). ${ }^{\mathrm{ii}}$ Moreover, when participants are asked to classify stimuli on one dimension, they are better able to ignore irrelevant stimulus characteristics when stressed than when not stressed (Chajut \& Algom, 2003). These findings suggest that arousal and stress enhance the priority of goal-relevant information, while diminishing the priority of goal-irrelevant information, which should have consequences for later memory (for more about the possible role of goal relevance in emotional memory narrowing effects see Levine \& Edelstein, 2009).

At first glance, other findings appear to contradict the idea that arousal enhances the priority of goal-relevant information. For instance, when participants compare the similarity of two

\footnotetext{
ii In Cornsweet's study, the peripheral light cues predicted the onset of a central light that required a fast keypress; participants' reaction times to the central lights were speeded up more by the peripheral warning cues in the stress condition.
} 
houses in the presence of two distracter faces, their performance drops when the facial expressions are emotional (Vuilleumier, Armony, Driver, \& Dolan, 2001). But such results are expected when an arousal-eliciting stimulus is in direct competition with the taskrelevant stimulus, because emotionally arousing stimuli themselves have high priority. Arousal-biased competition predicts that when arousal is induced in a way where the arousing stimulus is not in direct competition with the task-relevant stimuli, processing of neutral goal-relevant stimuli should be enhanced (e.g., Chajut \& Algom, 2003; Cornsweet, 1969; Hockey, 1970b), while the processing of less relevant stimuli should be reduced (e.g., Callaway \& Thompson, 1953; Hockey, 1970a; Nobata, Hakoda, \& Ninose, 2009).

Consistent with this hypothesis, hearing an arousing word enhances one's ability to identify briefly presented words that follow, whereas seeing an arousing word impairs subsequent visual word identification (Zeelenberg \& Bocanegra, 2010). When presented visually, the arousing stimuli are in direct competition for visual processing with the target words, whereas presenting the stimuli in two modalities reduces competition. When presented in the same modality, the competition between the arousing cue and the target word can be reduced by increasing the interval between them, or by making the cue presentation extremely brief (Bocanegra \& Zeelenberg, 2009a). Such manipulations can flip the effects of an emotional cue on subsequent word identification from impairment to enhancementallowing a demonstration of both emotion-induced "blindness" and "hypervision" in the same study.

Taken together, these results conflict with theoretical accounts that emotional arousal narrows the attentional spotlight, leading to enhanced processing of spatially central and impaired processing of spatially peripheral information. Instead, they indicate that arousal biases attention towards goal-relevant or perceptually salient stimuli, regardless of their spatial location. Unfortunately, observing this attentional bias is complicated by the fact that the source of the arousal is often also a prioritized stimulus that competes for mental representation.

\section{Arousal-Biased Competition in Binocular Rivalry}

When two different images are separately presented to each eye, one does not experience a constant blurred combination of the two images. One's sensory experience instead oscillates between coherent representations of each image, a phenomenon known as binocular rivalry (Blake \& Logothetis, 2002). The duration of time that either image occupies awareness can be controlled by focusing attention to particular features of the image (Chong \& Blake, 2006) or its global configuration (Mitchell, Stoner, \& Reynolds, 2004). Likewise, perceptual features, such as visual contrast, also influence the length of time a stimulus dominates awareness (Chong \& Blake, 2006).

Emotional arousal influences this type of visual competition. During rivalrous trials, emotional pictures dominate awareness longer than do neutral pictures (Alpers \& Pauli, 2006). Studies that control for low-level perceptual differences suggest that arousal is the factor driving this perceptual bias, as grating patterns paired with electric shock (Alpers, Ruhleder, Walz, Muhlberger, \& Pauli, 2005) and schematic faces displaying negative expressions (Alpers \& Gerdes, 2007) dominate awareness for longer than equivalent nonarousing stimuli. Moreover, people are aware of grating patterns superimposed on faces expressing positive or negative expressions for longer than gratings superimposed on neutral faces (Bannerman, Milders, De Gelder, \& Sahraie, 2008, Fig. 4). These effects can be observed for emotional stimuli of either valence, and a direct comparison of valence and arousal suggests that arousal is the emotional component driving this perceptual bias (Sheth \& Pham, 2008). 
How does $\mathrm{ABC}$ theory account for these effects? In the procedure depicted in Fig. 4, participants were told to focus only on the gratings appearing in the white circle and to indicate the grating orientations. Thus, participants in that study had a top-down goal that gave the gratings priority. When focusing on a particular grating, if the background face evoked arousal (i.e., had an emotional expression), that increased the competitive advantage of that grating over the one being presented to the other eye.

\section{Arousal Makes it More Difficult to Keep Track of Multiple Items}

In the studies reviewed so far, stimuli either varied in priority or just one stimulus was the focus of attention at a time, allowing some information to benefit from arousal-biased competition. However, having multiple high priority representations competing with each other can lead to overall suppression, as illustrated in Fig. 1B. ABC theory predicts that arousal increases such mutual inhibitory effects. To maintain multiple representations in working memory, one must continuously cycle through them to ensure that each one remains active. When experiencing arousal, each time a stimulus representation is refreshed, there is an additional cost for competing stimuli. If all of the stimuli have equal priority, the result will be mutual inhibition and an overall decrement in working memory performance.

Consistent with this possibility, after viewing a slide show of negative arousing pictures, participants were worse at tracking the location of multiple moving dots than were participants who viewed a slide show of neutral pictures (Morelli \& Burton, 2009). Likewise, when shown a sequence of four pictures, each appearing in a different location, memory for the picture-location pairs over a short delay was worse if the four pictures were arousing (either positive or negative) than if they were neutral (Mather, et al., 2006; Mitchell, Mather, Johnson, Raye, \& Greene, 2006). These findings suggest that arousal makes it more difficult to maintain multiple representations of equal priority in working memory.

\section{Brain Mechanisms of Arousal-Biased Competition and Top-Down Goals}

As discussed earlier, a signature of biased competition is that the same neuron shows different response properties depending on how relevant the stimulus is to current goals. But how are top-down attentional goals represented? Much research suggests that a frontoparietal attention system comprised of parts of the intraparietal cortex and superior frontal cortex plays a key role in anticipating and implementing goal-directed selection both in attention (Corbetta \& Shulman, 2002) and in memory retrieval (Cabeza, Ciaramelli, Olson, \& Moscovitch, 2008).

As we already discussed, emotional arousal amplifies the effects of top-down attentional goals (Phelps, et al., 2006; Schupp, et al., 2007). One possibility is that the amygdala drives these arousal effects by enhancing the impact of top-down attentional goals in the frontoparietal network. Some initial evidence consistent with this possibility comes from an fMRI study in which participants were asked to detect a face and a scene presented near each other in a rapid stream of visual images (Lim, Padmala, \& Pessoa, 2009). Some of the target faces and scenes were previously conditioned to be arousing and some to be neutral. As in previous studies (Anderson \& Phelps, 2001; De Martino, Kalisch, Rees, \& Dolan, 2009), participants were less likely to show an attentional blink (inability to detect the second target) when the second target was arousing than when it was not - even though in this study, the arousing stimuli were perceptually identical to the non-arousing stimuli. Furthermore, when participants correctly identified the targets, they showed greater amygdala activation for those conditioned to be arousing than for the non-arousing targets. Most interesting however, was that a trial-by-trial analysis of activity revealed that the influence of the amygdala on visual cortical responses was partially mediated by the medial 
frontal gyrus, part of the frontoparietal attention network. Thus, the amygdala may modulate activity in the frontoparietal attention network to bias attention towards high priority stimuli. This possibility fits with evidence that the amygdala activates when stimuli are potentially goal-relevant (e.g., Cunningham, Raye, \& Johnson, 2005; Sander, Grafman, \& Zalla, 2003) or have high perceptual salience within an emotional context (Attar, Muller, Andersen, Buchel, \& Rose, 2010).

In Lim et al.'s attentional blink paradigm, having targets be emotionally arousing enhanced participants' ability to carry out their goal of detecting the target. However, emotionally arousing stimuli can also distract people from their current goal, as arousing stimuli attract attention themselves. In that case, one might expect the amygdala to still modulate activity in the frontoparietal attention network, but rather than enhancing goal-directed selection, the amygdala should diminish the impact of goal-directed selection by prioritizing the emotionally relevant distractor. Consistent with this possibility, when focusing on taskrelevant stimuli in the presence of emotional distractors, amygdala activity increases while activity in the frontoparietal network decreases (Dolcos \& McCarthy, 2006; Mitchell, et al., 2008). These findings and those of Lim et al. (2009) suggest that the amygdala influences activity in the frontoparietal attention network-either increasing or decreasing how much attention is guided by top-down goals, which depends on whether attending to the source of the arousal is consistent with current task goals or not.

When arousing stimuli distract from current task goals, interactions between the amygdala and brain regions involved in resolving interference or conflict (such as the ACC or left inferior frontal cortex) may help to bias attention toward the emotionally arousing stimuli, or may help to counter the emotional distraction. In general, the ACC activates in situations involving conflict in information processing (Botvinick, Cohen, \& Carter, 2004; Carter \& van Veen, 2007). In one study amygdala activity correlated with anterior and posterior cingulate cortices in the presence of distracting emotional images (Mitchell, et al., 2008). Likewise, when masked fearful faces are used to orient attention to the spatial location of dot probes, amygdala activity was correlated with ACC activity and the amygdala-ACC correlation predicted attentional orienting to the masked fearful faces (Carlson, Reinke, \& Habib, 2009). Thus, the ACC may help disengage attention from other stimuli and redirect it towards emotionally arousing stimuli.

The left inferior frontal cortex plays a key role in resolving interference (Aron, Robbins, \& Poldrack, 2004; Jonides \& Nee, 2006) and one study found that its activity correlated with the amygdala when distracting emotional stimuli were present (Dolcos, Kragel, Wang, \& McCarthy, 2006). However, unlike the ACC activity in other studies, the inferior frontal cortex activity was associated with greater success in avoiding emotional distraction, rather than with orienting towards the emotional stimuli - thus the left inferior frontal cortex may provide top-down modulation of the amygdala, reducing the degree to which distracting emotional stimuli dominate attention.

\section{Summary of Evidence for Arousal-Biased Competition in Perception}

The studies reviewed above reveal that emotional arousal leads to a "winner-takes-more" effect in which already conspicuous stimuli gain priority, while lower priority stimuli are further suppressed. For instance, hearing arousing sounds before viewing a set of letters makes the high contrast letters even more conspicuous than the low contrast letters (Sutherland \& Mather, in preparation). When one eye is shown an emotionally arousing image and the other a neutral image, perception of the images alternates between them - but the emotionally arousing image tends to win the binocular rivalry competition for longer intervals (Alpers \& Gerdes, 2007; Alpers \& Pauli, 2006; Bannerman, et al., 2008; Sheth \& Pham, 2008). 
Arousal also amplifies the effects of directed attention towards one target stimulus or location (Phelps, et al., 2006; Schupp, et al., 2007), consistent with the ABC hypothesis that arousal enhances the effects of top-down relevance. However, when there are multiple stimuli competing for dominance, arousal interferes with distributing attention across multiple stimuli (Morelli \& Burton, 2009) and maintaining multiple representations in working memory (Mather, et al., 2006; Mitchell, et al., 2006). This arousal-based impairment when multiple stimuli are equally the target of attention is consistent with the idea that when adjacent strong representations compete, it leads to mutual interference (Fig. 1B).

The $\mathrm{ABC}$ effects described in this section are likely mediated by interactions between the amygdala and attention networks in the brain. For instance, there is evidence that the amygdala interacts with the frontoparietal attention network to enhance the priority of emotional stimuli that are the target of attentional goals (Lim, et al., 2009). However, further research is needed to determine whether the amygdala helps to bias competition to favor non-arousing but high priority stimuli during episodes of arousal.

\section{Arousal-Biased Competition During Encoding Shapes Memory}

In this section, we turn to the emotional memory effects outlined in Table 1 and make the case that the first three of these effects and their apparent contradictions in the literature can be explained by arousal-biased competition during encoding affecting what is later remembered.

\section{Memory Narrowing}

In the 1950's, Callaway and colleagues introduced the idea that stress narrows attention, arguing that, "a narrowed focus of attention (i.e., a decreased influence of peripheral factors) seems related to some neurophysiological component of acute stress" (Callaway \& Dembo, 1958, p. 74). Easterbrook's (1959) review of the literature argued that emotional arousal reduces the number of cues utilized in a task, contending that arousal and stress did not uniformly reduce cue utilization, but instead limited the use of peripheral (temporarily irrelevant) cues in favor of central (immediately relevant) cues. Subsequent researchers suggested that arousal also has opposite effects on memory for central and peripheral details, enhancing memory for central detail at the cost of peripheral detail (for reviews see Christianson, 1992; Levine \& Edelstein, 2009; Reisberg \& Heuer, 2004). A classic example of arousal's effect on central versus peripheral details is the 'weapon focus effect,' in which the presence of a weapon reduces eyewitness identification of the perpetrator (Loftus, Loftus, \& Messo, 1987; Steblay, 1992). Other examples consistent with memory narrowing come from studies examining memory for emotionally arousing objects embedded within emotionally neutral scenes. When a negative arousing object, such as a snake or a demolished vehicle, is placed in front of a neutral background, such as a desert or a city street, people remember the arousing central objects better than the neutral objects (Kensinger, Garoff-Eaton, \& Schacter, 2007; Kensinger, Gutchess, \& Schacter, 2007; Waring \& Kensinger, 2009). This emotional memory advantage creates a trade-off, however, as memory is worse for the background scenes behind the arousing objects than for background scenes behind neutral objects.

Emotionally provocative items, such as weapons and snakes, have high priority and also increase arousal. Thus, memory narrowing accounts and $\mathrm{ABC}$ theory both predict better memory for a central arousing stimulus, and worse memory for surrounding information, compared to when the emotionally arousing stimulus is replaced by something neutral. However, $\mathrm{ABC}$ theory states that instead of specifically benefiting central information at the cost of peripheral information, emotional arousal enhances the representation of whatever 
has the highest priority (which often is central information, but not always) and impairs representations of stimuli that are lower priority. Thus, if a plot-irrelevant background stimulus were prioritized for some reason (such as moving in a perceptually salient way), participants experiencing heightened levels of arousal would have an additional benefit in memory for that stimulus.

Unfortunately, studies in the memory narrowing literature rarely separate the source of emotion and the focus of attention. Instead, memory narrowing studies typically induce emotional responses by introducing an arousing central stimulus, such as a wounded woman at the scene of an accident, and compare memory for details of the central stimulus with those of a less arousing central stimulus (e.g., Brown, 2003; Christianson, Loftus, Hoffman, \& Loftus, 1991). Thus, the emotion-evoking stimulus and the central stimulus are confounded.

One study (Laney, Campbell, Heuer, \& Reisberg, 2004) that attempted to separate the source of emotional arousal and the central target of the memory test had participants watch a nearly identical slide show manipulating emotion by the type of narrative that accompanied the slides. In the first experiment, participants exposed to the emotional narrative had better memory than those who heard a neutral narrative, with the enhancement in memory being largest for the gist of the story line rather than for the specific contents of the slides. No significant memory impairment was observed in the emotional condition for central or peripheral visual details. In the second experiment, with a different set of slides and narratives, participants in the emotional group showed similar enhancements in memory for the narration gist, narration details, visual central details and visual peripheral details. Thus, the findings argue against a memory narrowing account. However, it is hard to know how much the effects in this study were due to arousal and how much to interest level in the story line, as the mean heart rate did not differ significantly across the two conditions.

Furthermore, much of the enhancement in memory in the emotion condition was for gist and details of the narrative, which was where the arousal was manipulated. Thus, even this study failed to thoroughly separate the emotion elicitor and the attentional focus.

Another study that reveals limitations of the narrowing account had participants view an arousing or non-arousing picture in a non-central location on the screen (Mather, Gorlick, \& Nesmith, 2009). One group viewed each picture with a "bystander" picture shown on the screen simultaneously whereas the other group viewed the pictures placed on a wallpaperlike background. Arousing pictures significantly impaired memory for the backgrounds but not the bystander pictures. A narrowing account would predict similar impairments for both types of stimuli as they were both spatially peripheral to the arousing picture. In contrast, $\mathrm{ABC}$ theory predicts greater impairment for the background wallpaper than for the bystander picture, as the spatial arrangement would lead to greater baseline differences in priority between the background wallpaper and foreground arousing picture than between the two foreground pictures.

In our view, findings that support memory narrowing accounts are actually instances of arousal strengthening mental representations of high priority stimuli (see also Levine \& Edelstein, 2009). Because of their perceptual salience and goal relevance, when emotional items evoke arousal, that arousal is likely to bias competition in their favor. Thus, when the arousing items are central, it may appear to be a memory narrowing effect. However, in general, arousal should increase the effects of competition between different representations, leading to winner-take-more and loser-take-less effects, regardless of whether the "winner" (the highest priority aspect of the experience) is spatially central or not. 


\section{Emotional Arousal Enhances Memory for Gist but not Detail}

Although the memory narrowing effects described in the previous section appear in many studies, distinguishing central and peripheral information is not sufficient to account for all the selective effects of emotional arousal on memory. For instance, inducing emotional arousal by interspersing a slide show with emotional pictures instead of neutral pictures increases the relative advantage in memory 24 hours later for the gist of the rest of the slide show compared with its details (Adolphs, Tranel, \& Buchanan, 2005). This emotion enhancement effect for gist memory is not just an encoding effect, as it is also seen when participants first view and rate pictures and then watch a positive or negative arousing video instead of a neutral video (Liu, Graham, \& Zorawski, 2008). A week later, participants who had viewed arousing videos had better gist memory for the preceding pictures but not better detail memory. Other studies have also found that inducing an emotional focus increases schema reliance in memory (Mather \& Johnson, 2003; Mather, Johnson, \& De Leonardis, 1999), that exercise-induced arousal increases the memory strength of stereotype consistent adjectives relative to neutral adjectives (Kim \& Baron, 1988), and that stress induced before learning lists of words increases false recognition of semantically related words (Payne, Nadel, Allen, Thomas, \& Jacobs, 2002). Furthermore, whereas controls and patients with unilateral amygdala damage showed better memory for the gist of emotional pictures than the gist of neutral pictures, a patient with bilateral amygdala damage was worse at memory for the gist of emotional pictures than of neutral pictures (Adolphs, Denburg, \& Tranel, 2001).

The notion that arousal enhances gist but not detail is challenged, however, by findings that memory is better for the specific details of emotional objects (such as a hand grenade) than for the specific details of neutral objects (such as a basket; Kensinger, Garoff-Eaton, \& Schacter, 2006; Kensinger, Garoff-Eaton, et al., 2007). Thus, the idea that arousal enhances memory for gist but not detail does not hold up across all contexts; some other explanation is needed for the pattern of findings.

We argue that $\mathrm{ABC}$ theory can account for when arousal will enhance memory for gist and when it will enhance memory for details. In most events that have an overarching theme or narrative, the gist or schema is likely to be more salient and have more relevance than the details. In these types of events, increasing emotional arousal should increase the dominance of gist over details through arousal-biased competition, which favors high priority information. Indeed, consistent with ABC theory, whether emotional stimuli lead to a gist/ detail trade-off has been shown to depend on what has highest prominence during encoding (Kensinger, Garoff-Eaton, et al., 2007). In an initial experiment, when participants passively viewed a series of unrelated slides that each had a central item presented on a background, emotionally negative central items (such as a crashed car) yielded enhanced memory for both the specific details and the gist of that item but also decreased memory for the specific details of the background. Thus, this experiment demonstrated that emotional stimuli do not always lead to gist/detail trade-offs; emotion can enhance memory for details of the most prominent item in the scene (see also Kensinger, et al., 2006). Furthermore, in a subsequent experiment in which participants were asked to describe the details of each scene such that an artist could reproduce them, central emotional items were associated with advantages for both gist and detail memory for background contexts as well as for the central items. These studies indicate that neither the gist/detail nor the central/periphery distinction can accurately predict what will be enhanced by emotional arousal. Instead, a more plausible account of these differences in memory requires distinguishing what has priority during encoding. 


\section{Arousal Enhances Within-Object Memory Binding}

A number of studies have found better memory for the color, location or visual details of emotionally arousing items than non-arousing items (D'Argembeau \& Van der Linden, 2004; Doerksen \& Shimamura, 2001; Kensinger \& Corkin, 2003; Kensinger, et al., 2006; MacKay \& Ahmetzanov, 2005; MacKay, et al., 2004; Mather, et al., 2009; Mather \& Nesmith, 2008; Mather \& Sutherland, 2009; Nashiro \& Mather, in press; but see Davidson, McFarland, \& Glisky, 2006). In contrast, people do not usually have enhanced memory for the associations between emotionally arousing items and other items shown at the same time (Mather, et al., 2009; Mather \& Sutherland, 2009; Nashiro \& Mather, in press; but see Guillet \& Arndt, 2009).

Mather's (2007) object-based framework proposed that arousal-enhanced memory binding for within-object features occurs because: 1) as outlined by Treisman (1999), perceptually binding features such as color and location to an object requires focused attention; 2) emotionally arousing stimuli attract focused attention; and 3) the ensuing perceptual binding advantage for emotionally arousing items is maintained during working memory, where emotionally arousing items dominate the competition for mental resources. Kensinger $(2007,2009)$ outlined a similar model in which negative emotional arousal (rather than emotional arousal more generally) enhances memory for the intrinsic details of negative events, while impairing memory for extrinsic contextual details.

A challenge to these ideas is that one recent study found better memory for the association between two words when one of the words was emotionally arousing than when neither was arousing (Guillet \& Arndt, 2009). Thus, the way that arousal affects memory binding cannot be predicted solely by whether the information to be bound is intrinsic to an item or is distinct.

According to $\mathrm{ABC}$ theory, arousal should enhance processing of whatever has highest priority and impair processing of lower priority information, regardless of whether its priority is due to bottom-up perceptual salience, or top-down attentional focus. The theory has implications for associative memory as well as for item memory. By winning the competition for processing resources, high priority items should garner not only better memory for their identity (e.g., ball) but also for their intrinsic features and location (e.g., red, rubber, in the corner). Thus, arousal may enhance associative memory for the features of high priority items. Furthermore, if the association between two items is high priority (e.g., it was Emily who threw the ball), that association should be further enhanced in memory by arousal.

$\mathrm{ABC}$ theory can account for findings that arousal typically enhances memory for the intrinsic features of arousing pictures or words (for a review see Mather, 2007), as the arousal associated with those stimuli gives them higher priority. The theory can also explain why viewing an arousing item does not enhance memory for associations between that item and other competing non-arousing items (Mather, et al., 2009) unless participants are asked to learn the associations at encoding — a task goal that should prioritize the item-item associations (Guillet \& Arndt, 2009). In contrast, Mather's (2007) object-based framework cannot account for situations in which arousal enhances memory for item-item associations.

In their "binding hypothesis," MacKay and colleagues argue that emotional reactions enhance binding of the source of the emotion to salient aspects of the context (Hadley \& MacKay, 2006; MacKay \& Ahmetzanov, 2005). Although this binding hypothesis can account for Guillet and Arndt's findings (insofar as the other item is a salient part of the context), it focuses only on binding information to the emotional item and does not make predictions about binding for other high priority information. 
$\mathrm{ABC}$ theory goes a step further by predicting that arousal will enhance binding for high priority information regardless of whether that information is emotional or not. Consistent with this prediction, participants exposed to a constant loud noise during their experiment session showed stronger effects of top-down priority (Smith, 1982). Specifically, if told to prioritize memory for the word locations over the word order, the aroused subjects showed better memory for the location and slight impairment in memory for the order compared with control (soft noise) participants. If told to prioritize memory for the word order, the aroused participants showed better memory for word order and slightly worse memory for the word location than control participants who were given the same encoding instructions but were not exposed to the arousing loud noise.

Thus, consistent with $\mathrm{ABC}$ theory, arousal enhances memory binding for high priority information, regardless of whether the prioritized information is arousing or not. Moreover, arousal-enhanced memory binding is not limited to intrinsic features of single items, but can enhance binding (associations) of two separate items in memory as well; assuming the association between the two items has high priority when arousal is experienced.

\section{Arousal-Biased Competition in Memory Consolidation}

So far we have focused on how arousal affects initial perception and encoding of information, arguing that arousal amplifies competition between high and low priority stimuli. Here we suggest that this $\mathrm{ABC}$ effect continues after initial perception, amplifying memory consolidation for high priority stimuli, while decreasing memory consolidation for low priority stimuli (Fig. 5). Furthermore, we extend this hypothesis to stimuli experienced prior to the onset of arousal/stress, arguing that arousal/stress amplifies pre-existing priority differences among stimuli with currently active mental representations. These mechanisms can account for the two remaining arousal effects described in Table 1.

\section{Arousal Creates Retrograde Amnesia}

When an emotional picture or word is an "oddball" in a list—in other words, it is different from all the rest of the items-it will typically impair memory for stimuli preceding or following it more than non-emotional oddballs do (Bornstein, Liebel, \& Scarberry, 1998; Detterman \& Ellis, 1972; Ellis, Detterman, Runcie, McCarver, \& Craig, 1971; Erdelyi \& Blumenth, 1973; Hadley \& MacKay, 2006; Hurlemann, et al., 2005; Knight \& Mather, 2009; MacKay, et al., 2004; Miu, Heilman, Opre, \& Miclea, 2005; Runcie \& Obannon, 1977; Schmidt, 2002; Strange, Hurlemann, \& Dolan, 2003). However, when asked to study one neutral face and shown either an emotional or a neutral picture immediately afterwards, a week later participants remembered the faces that appeared before the emotional pictures better than those that appeared before the neutral pictures (Anderson, Wais, \& Gabrieli, 2006). This raises the question of how arousal can sometimes enhance and sometimes impair memory for preceding neutral stimuli.

In oddball-type studies, participants are typically presented with many lists of perceptually similar neutral items, with one distinctive oddball in each list. Thus, items preceding the oddball would be low priority relative to the oddball, which was quite distinctive and memorable. Having the oddball item be arousing further suppresses the low priority nearby neutral items.

However, if a neutral item could be made to be high priority, then having an arousing stimulus appear next should enhance later memory for the neutral item. Indeed, emotional pictures did enhance memory for preceding pictures when, on each trial, participants were shown one neutral face followed by a modulator emotional or neutral picture (Anderson, et al., 2006). Participants' task was to indicate whether they would remember the face later or 
not, which should have given the face priority. Furthermore, the face was the only stimulus shown before the modulator picture, reducing competition among preceding items compared with the experiments with oddballs embedded in lists of neutral items.

These findings across different studies suggest the highest priority stimuli prior to the onset of emotional arousal or stress will be enhanced in long-term memory, while lower priority stimuli prior to the onset of arousal/stress will be suppressed. Results from a study showing both retrograde impairment and enhancement in the same paradigm support this hypothesis (Knight \& Mather, 2009). This study tested a number of potential factors that might account for the conflicting effects of emotional stimuli on memory for preceding items and found that the key factors were both the delay and the amount of encoding effort directed towards an item. Retrograde amnesia effects were most likely when there were larger sets of neutral items appearing before each emotional item and when memory was tested immediately. In contrast, retrograde enhancement effects only appeared after a longer delay (one week rather than within the same session) and only for preceding items that participants either were trying to learn or for those that they had successfully retrieved on an immediate test. Thus, retrograde enhancement for items seen before emotionally arousing items depends both on the initial priority of the neutral preceding item and on the passage of time.

\title{
5.Arousal Enhances Consolidation for Emotional Items
}

The idea that arousal experienced shortly after encoding new information will enhance or impair memory consolidation depending on the information priority can also help explain some other contradictory findings in the literature. Some studies find that post-encoding arousal enhances memory for emotional items but impairs or does not affect memory for neutral items, when emotional and neutral items are intermixed on a study list (Buchanan \& Lovallo, 2001; Cahill, Gorski, \& Le, 2003; Liu, et al., 2008; Smeets, Otgaar, Candel, \& Wolf, 2008; see also Abercrombie, Speck, \& Monticelli, 2006; Segal \& Cahill, 2009). However, when asked to memorize only neutral information and then given an arousal induction or shown arousing stimuli, participants show enhanced memory later for the neutral information (Anderson, et al., 2006; Andreano \& Cahill, 2006; Knight \& Mather, 2009; Nielson \& Powless, 2007; Nielson, Yee, \& Erickson, 2005; see also Maheu, Joober, Beaulieu, \& Lupien, 2004).

\begin{abstract}
$\mathrm{ABC}$ theory suggests that these mixed findings about whether post-learning arousal enhances consolidation of neutral information arise from differences in stimulus priority during initial encoding. Specifically, for the studies using emotional/neutral mixed slide shows (Cahill, et al., 2003; Buchanan \& Lovallo, 2001; Liu, et al., 2008), ABC theory suggests that post-encoding stress enhances memory for arousing stimuli because these stimuli are more conspicuous than the competing neutral stimuli. In other studies that ask participants to learn emotionally neutral material, the highest priority information should be found among the neutral to-be-learned material due to its top-down goal relevance, and therefore gain from arousal-biased competition. ${ }^{\text {iii }}$ In contrast, goal-irrelevant information from the experimental context should be less likely to be remembered. In other words, the marker the brain uses to have post-encoding arousal or stress selectively enhance certain information from an event is priority (Fig. 5).
\end{abstract}

\footnotetext{
iii In contrast with other studies, Henckens et al. (2009) found no difference in memory for arousing and neutral pictures when encoded in between the presentation of stress-inducing or neutral video clips. The content of the pictures overlapped with the contents in the film, so as to construct a 'continuous and coherent stressful episode.' This may have attenuated any biased competition advantage for arousing pictures, as the neutral pictures may have been equally the focus of attention because of their conceptual links with the arousing pictures and the stress-inducing movie clips.
} 
Consistent with this argument, there is evidence from the animal literature that post-learning induction of epinephrine (e.g., Jurado-Berbel, Costa-Miserachs, Torras-Garcia, Coll-Andreu, \& Portell-Cortes, 2010) or norepinephrine (Roozendaal, Castello, Vedana, Barsegyan, \& McGaugh, 2008) can enhance memory for neutral information that was the focus of attention shortly before the stress hormone induction. Furthermore, Roozendaal et al. (2008) infused norepinephrine or the $\beta$-adrenoceptor antagonist propranolol directly into the basolateral amygdala after rats were presented with two versions of a novel object, linking these effects to the amygdala. They found dose-dependent memory enhancement for the object 24 hours later in the norepinephrine condition and dose-dependent memory impairment in the propranolol condition. Thus, noradrenergic activation of the basolateral amygdala modulates long-term consolidation of memory for novel information that was just learned, even when that information was not inherently emotional.

A recent study with rats demonstrates increased neural representation of stimuli perceived during amygdala activation (Chavez, McGaugh, \& Weinberger, 2009). In this experiment, rats under general anesthesia heard tones. Initially, the researchers used electrodes placed in the primary auditory cortex to find out which tone frequency produced the greatest neuronal activity for particular receptive fields. They then selected a different tone and played that tone 100 times overlapping with brief stimulation of the basolateral amygdala. If the amygdala stimulation occurred $1 \mathrm{~s}$ after tone onset, there was a shift in the nature of the receptive field, such that over the next 75 minutes, it shifted gradually to become most responsive to the new tone, rather than to its original preferred tone. In contrast, if the amygdala stimulation was a little later after the tone onset $(1.6 \mathrm{~s})$, there was little evidence of a shift in what tones were represented by that receptive field. This suggests that, at least under anesthesia, amygdala activation must occur very closely in time to the auditory stimulus in order to modulate its representation. More generally, these findings suggest that the basolateral amygdala modulates memory consolidation by shifting the tuning of neurons to represent sensory memories for salient events that occurred during amygdala activation. This may be one way in which arousal biases neural representation in favor of prominent events occurring close in time to an increase in arousal.

From the perspective of our arousal-biased competition theory, whether or not arousalinduced amygdala activation enhances long-term consolidation of information encoded prior to or during arousal onset depends on each stimulus' priority during encoding. When the stimulus itself is emotionally arousing, it gains priority over other non-emotional stimuli. Thus, arousal-biased competition will lead to enhanced memory consolidation of emotional stimuli on intermixed lists. However, arousal-biased competition mechanisms can also enhance memory for high priority non-emotional stimuli. Future studies should manipulate the bottom-up perceptual salience or top-down goal relevance of neutral material encoded prior to evoked emotional arousal or pharmacological manipulations of epinephrine and cortisol, as this would allow a direct test of ABC theory in the domain of long-term memory consolidation.

\section{Arousal Versus Valence Effects}

In this paper we have argued that arousal stimulates the amygdala to modulate sensory processing, frontoparietal attention networks and memory consolidation of high priority information in ways that increase the selectivity of attention and memory for arousing experiences. But what about valence, the other primary dimension of emotion? How might it affect biased competition?

Since arousal activates the amygdala regardless of whether it is elicited by positive or negative stimuli (e.g., Anderson, et al., 2003; Cunningham, Raye, \& Johnson, 2004; 
Hamann, Ely, Hoffman, \& Kilts, 2002; Mather, et al., 2004), it makes sense that positive and negative sources of arousal would have similar effects on how the amygdala biases attention. Indeed, previous studies suggest that arousal is more of a critical factor than valence in biasing competition. Both positive and negative arousing stimuli affect attentional selectivity, for instance in binocular rivalry (Sheth \& Pham, 2008) and in the attentional blink (Anderson, 2005; Keil \& Ihssen, 2004). Likewise, both erotica and mutilation pictures amplify the effects of attention as measured by ERP (Schupp, et al., 2007). Positive and negative arousing pictures yield similar enhancements in location memory binding (Mather \& Nesmith, 2008; Mather \& Sutherland, 2009). And negative and positive arousal also have similar effects on long-term memory consolidation; watching either a positive or negative arousing video clip enhances consolidation of high priority items encoded just before the video (Liu, et al., 2008; Nielson \& Powless, 2007).

However, even if arousal evoked by positive or negative stimuli affects biased competition in the same manner, valence may influence other aspects of cognitive processing differently. One intriguing possibility is that negative emotion impairs semantic processing but enhances perceptual processing, whereas the reverse is the case for positive emotion (for a review see Kensinger, 2009). Neuroimaging studies have found that negative items that are later remembered recruit brain regions involved in sensory processing more than positive items that are later remembered (Kensinger \& Schacter, 2008; Mickley \& Kensinger, 2008), whereas the encoding of positive items is associated with greater activation in regions associated with semantic or conceptual processing (Kensinger \& Schacter, 2008). A behavioral study in which participants were shown a picture on each trial, followed by a semantic or perceptual judgment about an object, found that, relative to neutral or positive pictures, negative pictures slowed subsequent reaction times on semantic tasks but not on perceptual tasks (Sakaki, Gorlick, \& Mather, under review). Negative mood inductions also impair semantic priming compared with positive mood inductions or baseline (Storbeck \& Clore, 2008).

In addition, others have found evidence that exposure to positive stimuli broadens cognitive processes, including one's scope of attention (Fredrickson, 1998; Fredrickson \& Branigan, 2005), which results in increased perceptual processing of task-irrelevant stimuli (Rowe, Hirsh, \& Anderson, 2007). After viewing a series of positive images, viewing task-irrelevant houses in the periphery of one's visual field increased responses in the parahippocampal place area (PPA), while the opposite effect was observed upon exposure to negative pictures (Schmitz, De Rosa, \& Anderson, 2009). Increased processing of task-irrelevant information during positive arousal would conflict with the predictions made by arousal-biased competition. However, it is important to note that these studies did not use highly arousing stimuli. The positive and negative stimuli used by Rowe et al. differed from neutral stimuli only in terms of valence, not arousal. Similarly, Schmitz et al. used positive and negative stimuli that varied widely in terms of arousal, and specifically excluded high arousing stimuli such as mutilation and erotica. ABC theory would not predict differences between neutral and emotional stimuli when they evoke similar arousal responses.

These studies suggest that positive and negative affect may have opposite effects on selective attention at low levels of arousal. However, when primed with high approach motivated positive affect (via a cue indicating a potential reward for correct performance or via a picture of an appetitive picture), participants showed enhanced memory for words subsequently shown in the central task-relevant location and either no enhancement or impairment for words shown in peripheral task-irrelevant locations (Gable \& Harmon-Jones, 2010b). Positive stimuli cueing high approach motivation tend to have higher arousal than low-approach-motivation positive stimuli (Gable \& Harmon-Jones, 2010a), and thus high arousal positive stimuli seem to enhance memory for stimuli presented in the central task- 
relevant location but not memory for peripheral stimuli-a finding that is consistent with $\mathrm{ABC}$ predictions.

The studies outlined in this section suggest that negative and positive affect have opposite effects on perceptual and semantic processing. Furthermore, at low levels of arousal, positive and negative affect may influence perceptual processing differently. These effects are also likely to influence memory and may interact with arousal-biased competition effects.

\section{Conclusions}

Psychologists have long been fascinated by how emotional arousal affects perception, attention and memory. For instance, in 1890, William James wrote, "An impression may be so exciting emotionally as almost to leave a scar upon the cerebral tissues" (James, 1890, p. 670). Although a mere 10 pages later, when discussing forgetting, James noted that, "Selection is the very keel on which our mental ship is built," he did not link emotion and selection processes in memory. Most researchers followed James' lead, focusing on enhanced processing of emotionally arousing information. In recent years, research into the general mechanisms of arousal and memory has focused on the key role of the amygdala in enhancing perception and memory of emotionally arousing stimuli (for reviews see LaBar \& Cabeza, 2006; McGaugh, 2004; Murty, Ritchey, Adcock, \& LaBar; Payne \& Kensinger, 2010; Phelps, 2004). However, as reviewed in this paper and summarized in Table 1, enhanced memory for arousing information is only part of the pattern-there is also abundant evidence for arousal's selective effects in memory.

The arousal-biased competition theory outlined here involves some simple mechanisms that can account for a broad range of arousal-induced selectivity effects in memory, even findings that initially appear contradictory such as those in the middle and right-hand columns of Table 1 . ABC theory proposes that when initially processing information, arousal influences competition between different stimuli for mental resources, increasing processing of high priority stimuli and decreasing processing of low priority stimuli. Furthermore, $\mathrm{ABC}$ theory posits that arousal experienced during or just after an event biases memory consolidation in favor of high priority information from the event and against low priority information from that event. Priority is determined by bottom-up perceptual salience and top-down relevance.

Thus, arousal should enhance processing and consolidation of high priority information, regardless of whether the information has priority because of its bottom-up attention grabbing nature or because of top-down goals such as the desire to remember it later. This "winner-take-more" effect may be adaptive. Arousal is likely to be associated with challenging, important or threatening events, for which fast and focused responding is critical. Enhanced processing of salient, surprising or goal-relevant stimuli should improve performance under such circumstances. Later, remembering the high priority information from the event could improve future strategies for dealing with similar situations. But the increased advantage of high priority information comes at the expense of low priority information that garners even fewer neural resources under arousal than it would otherwise.

\section{References}

Abercrombie HC, Kalin NH, Thurow ME, Rosenkranz MA, Davidson RJ. Cortisol variation in humans affects memory for emotionally laden and neutral information. Behavioral Neuroscience. 2003; 117(3):505-516. doi: 10.1037/0735-7044.117.3.505. [PubMed: 12802879] 
Abercrombie HC, Speck NS, Monticelli RA. Endogenous cortisol elevations are related to memory facilitation only in individuals who are emotionally aroused (vol 31, pg 187, 2006). Psychoneuroendocrinology. 2006; 31(3):414-414. doi: 10.1016/j.psyneuen.2006.01.001.

Adolphs R, Denburg NL, Tranel D. The amygdala's role in long-term declarative memory for gist and detail. Behavioral Neuroscience. 2001; 115(5):983-992. doi: 10.1037//0735-7044.115.5.983. [PubMed: 11584931]

Adolphs R, Tranel D, Buchanan TW. Amygdala damage impairs emotional memory for gist but not details of complex stimuli. Nature Neuroscience. 2005; 8(4):512-518. doi: 10.1038/nn1413.

Alpers GW, Gerdes ABM. Here is looking at you: Emotional faces predominate in binocular rivalry. Emotion. 2007; 7(3):495-506. doi: 10.1037/1528-3542.7.3.495. [PubMed: 17683206]

Alpers GW, Pauli P. Emotional pictures predominate in binocular rivalry. Cognition \& Emotion. 2006; 20(5):596-607. doi: 10.1080/02699930500282249.

Alpers GW, Ruhleder M, Walz N, Muhlberger A, Pauli P. Binocular rivalry between emotional and neutral stimuli: A validation using fear conditioning and EEG. International Journal of Psychophysiology. 2005; 57(1):25-32. doi: 10.1016/j.ijpsycho.2005.01.008. [PubMed: 15893834]

Anderson AK. Affective influences on the attentional dynamics supporting awareness. Journal of Experimental Psychology-General. 2005; 134(2):258-281. doi: 10.1037/0096-3445.134.2.258. [PubMed: 15869349]

Anderson AK, Christoff K, Stappen I, Panitz D, Ghahremani DG, Glover G, et al. Dissociated neural representations of intensity and valence in human olfaction. Nature Neuroscience. 2003; 6(2):196202.

Anderson AK, Phelps EA. Lesions of the human amygdala impair enhanced perception of emotionally salient events. Nature. 2001; 411(6835):305-309. doi: 10.1038/35077083. [PubMed: 11357132]

Anderson AK, Wais PE, Gabrieli JDE. Emotion enhances remembrance of neutral events past. Proceedings of the National Academy of Sciences of the United States of America. 2006; 103(5): 1599-1604. doi: 10.1073/pnas.0506308103. [PubMed: 16434476]

Andreano JM, Cahill L. Glucocorticoid release and memory consolidation in men and women. Psychological Science. 2006; 17(6):466-470. doi: 10.1111/j.1467-9280.2006.01729.x. [PubMed: 16771794]

Aron AR, Robbins TW, Poldrack RA. Inhibition and the right inferior frontal cortex. Trends in Cognitive Sciences. 2004; 8(4):170-177. doi: 10.1016/j.tics.2004.02.010. [PubMed: 15050513]

Attar CH, Muller MM, Andersen SK, Buchel C, Rose M. Emotional processing in a salient motion context: Integration of motion and emotion in both V5/hMT + and the amygdala. Journal of Neuroscience. 2010; 30(15):5204-5210. doi: 10.1523/jneurosci.5029-09.2010. [PubMed: 20392942]

Baldi P, Itti L. Of bits and wows: A Bayesian theory of surprise with applications to attention. Neural Networks. 2010; 23(5):649-666. doi: 10.1016/j.neunet.2009.12.007. [PubMed: 20080025]

Bannerman RL, Milders M, De Gelder B, Sahraie A. Influence of emotional facial expressions on binocular rivalry. Ophthalmic and Physiological Optics. 2008; 28(4):317-326. doi: 10.1111/j. 1475-1313.2008.00568.x. [PubMed: 18565087]

Beck DM, Kastner S. Top-down and bottom-up mechanisms in biasing competition in the human brain. Vision Research. 2009; 49(10):1154-1165. doi: 10.1016/j.visres.2008.07.012. [PubMed: 18694779]

Berg DJ, Boehnke SE, Marino RA, Munoz DP, Itti L. Free viewing of dynamic stimuli by humans and monkeys. Journal of Vision. 2009; 9(5):15. doi: 1910.1167/9.5.19.

Birmingham E, Bischof WF, Kingstone A. Gaze selection in complex social scenes. Visual Cognition. 2008; 16(2-3):341-355. doi: 10.1080/13506280701434532.

Birmingham E, Bischof WF, Kingstone A. Get real! Resolving the debate about equivalent social stimuli. Visual Cognition. 2009a; 17(6-7):904-924. doi: 10.1080/13506280902758044.

Birmingham E, Bischof WF, Kingstone A. Saliency does not account for fixations to eyes within social scenes. Vision Research. 2009b; 49(24):2992-3000. doi: 10.1016/j.visres.2009.09.014. [PubMed: 19782100]

Blake R, Logothetis NK. Visual competition. Nature Reviews Neuroscience. 2002; 3(1):13-23. doi: $10.1038 /$ nrn701. 
Bocanegra BR, Zeelenberg R. Dissociating emotion-induced blindness and hypervision. Emotion. 2009a; 9(6):865-873. doi: 10.1037/a0017749. [PubMed: 20001129]

Bocanegra BR, Zeelenberg R. Emotion improves and impairs early vision. Psychological Science. 2009b; 20(6):707-713. doi: 10.1111/j.1467-9280.2009.02354.x. [PubMed: 19422624]

Bornstein BH, Liebel LM, Scarberry NC. Repeated testing in eyewitness memory: A means to improve recall of a negative emotional event. Applied Cognitive Psychology. 1998; 12(2):119_ 131. doi: 10.1002/(SICI)1099-0720(199804)12:2<119::AID-ACP500>3.0.CO;2-4.

Botvinick MM, Cohen JD, Carter CS. Conflict monitoring and anterior cingulate cortex: an update. Trends in Cognitive Sciences. 2004; 8(12):539-546. doi: 10.1016/j.tics.2004.10.003. [PubMed: 15556023]

Bradley MM, Miccoli L, Escrig MA, Lang PJ. The pupil as a measure of emotional arousal and autonomic activation. Psychophysiology. 2008; 45(4):602-607. doi: 10.1111/j. 1469-8986.2008.00654.x. [PubMed: 18282202]

Brown JM. Eyewitness memory for arousing events: Putting things into context. Applied Cognitive Psychology. 2003; 17(1):93-106. doi: 10.1002/acp.848.

Buchanan TW, Lovallo WR. Enhanced memory for emotional material following stress-level cortisol treatment in humans. Psychoneuroendocrinology. 2001; 26(3):307-317. doi: 10.1016/ S0306-4530(00)00058-5. [PubMed: 11166493]

Bundesen C. A theory of visual-attention. Psychological Review. 1990; 97(4):523-547. doi: 10.1037/0033-295X.97.4.523. [PubMed: 2247540]

Bundesen C, Habekost T, Kyllingsbaek S. A neural theory of visual attention: Bridging cognition and neurophysiology. Psychological Review. 2005; 112(2):291-328. doi: 10.1037/0033-295x. 112.2.291. [PubMed: 15783288]

Burke A, Heuer F, Reisberg D. Remembering emotional events. Memory \& Cognition. 1992; 20(3): 277-290.

Cabeza R, Ciaramelli E, Olson IR, Moscovitch M. The parietal cortex and episodic memory: an attentional account. Nature Reviews Neuroscience. 2008; 9(8):613-625. doi: 10.1038/nrn2459.

Cahill L, Gorski L, Le K. Enhanced human memory consolidation with post-learning stress: Interaction with the degree of arousal at encoding. Learning \& Memory. 2003; 10(4):270-274. doi: 10.1101/lm.62403. [PubMed: 12888545]

Callaway E, Dembo D. Narrowed attention: A psychological phenomenon that accompanies a certain physiological change. Archives of Neurology and Psychiatry. 1958; 79(1):74-90. [PubMed: 13486983]

Callaway E, Thompson SV. Sympathetic activity and perception: An approach to the relationships between autonomic activity and personality. Psychosomatic Medicine. 1953; 15(5):443-455. [PubMed: 13100547]

Calvo MG, Nummenmaa L. Detection of emotional faces: Salient physical features guide effective visual search. Journal of Experimental Psychology-General. 2008; 137(3):471-494. doi: 10.1037/ a0012771. [PubMed: 18729711]

Carlson JM, Reinke KS, Habib R. A left amygdala mediated network for rapid orienting to masked fearful faces. Neuropsychologia. 2009; 47(5):1386-1389. doi: 10.1016/j.neuropsychologia. 2009.01.026. [PubMed: 19428403]

Carter CS, van Veen V. Anterior cingulate cortex and conflict detection: An update of theory and data. Cognitive Affective \& Behavioral Neuroscience. 2007; 7(4):367-379. doi: 10.3758/CABN. 7.4.367.

Cave KR, Bichot NP. Visuospatial attention: Beyond a spotlight model. Psychonomic Bulletin \& Review. 1999; 6(2):204-223. [PubMed: 12199208]

Chajut E, Algom D. Selective attention improves under stress: Implications for theories of social cognition. Journal of Personality and Social Psychology. 2003; 85(2):231-248. doi: 10.1037/0022-3514.85.2.231. [PubMed: 12916567]

Chavez CM, McGaugh JL, Weinberger NM. The basolateral amygdala modulates specific sensory memory representations in the cerebral cortex. Neurobiology of Learning and Memory. 2009; 91(4):382-392. doi: 10.1016/j.nlm.2008.10.010. [PubMed: 19028592] 
Chelazzi L, Duncan J, Miller EK, Desimone R. Responses of neurons in inferior temporal cortex during memory-guided visual search. Journal of Neurophysiology. 1998; 80(6):2918-2940. [PubMed: 9862896]

Chelazzi L, Miller EK, Duncan J, Desimone R. Responses of neurons in macaque area V4 during memory-guided visual search. Cerebral Cortex. 2001; 11(8):761-772. doi: 10.1093/cercor/ 11.8.761. [PubMed: 11459766]

Chong SC, Blake R. Exogenous attention and endogenous attention influence initial dominance in binocular rivalry. Vision Research. 2006; 46(11):1794-1803. doi: 10.1016/j.visres.2005.10.031. [PubMed: 16368126]

Christianson S- , Loftus EF, Hoffman H, Loftus GR. Eye fixations and memory for emotional events. Journal of Experimental Psychology: Learning Memory and Cognition. 1991; 17(4):693-701. doi: 10.1037/0278-7393.17.4.693.

Corbetta M, Shulman GL. Control of goal-directed and stimulus-driven attention in the brain. Nature Reviews Neuroscience. 2002; 3(3):201-215. doi: 10.1038/nrn755.

Cornsweet DM. Use of cues in visual periphery under conditions of arousal. Journal of Experimental Psychology. 1969; 80(1):14-\&. doi: doi:10.1037/h0027115. [PubMed: 5787409]

Cunningham WA, Raye CL, Johnson MK. Implicit and explicit evaluation: fMRI correlates of valence, emotional intensity, and control in the processing of attitudes. Journal of Cognitive Neuroscience. 2004; 16(10):1717-1729. [PubMed: 15701224]

Cunningham WA, Raye CL, Johnson MK. Neural correlates of evaluation associated with promotion and prevention regulatory focus. Cognitive Affective \& Behavioral Neuroscience. 2005; 5(2):202211.

D'Argembeau A, Van der Linden M. Influence of affective meaning on memory for contextual information. Emotion. 2004; 4(2):173-188. doi: 10.1037/1528-3542.4.2.173. [PubMed: 15222854]

Davidson PSR, McFarland CR, Glisky EL. Effects of emotion on item and source memory in young and older adults. Cognitive Affective \& Behavioral Neuroscience. 2006; 6(4):306-322. doi: 10.3758/CABN.6.4.306.

De Martino B, Kalisch R, Rees G, Dolan RJ. Enhanced processing of threat stimuli under limited attentional resources. Cerebral Cortex. 2009; 19(1):127-133. doi: 10.1093/cercor/bhn062. [PubMed: 18448453]

Deco G, Rolls ET. Attention, short-term memory, and action selection: A unifying theory. Progress in Neurobiology. 2005; 76(4):236-256. doi: 10.1016/j.pneurobio.2005.08.004. [PubMed: 16257103]

Dehaene S, Kerszberg M, Changeux JP. A neuronal model of a global workspace in effortful cognitive tasks. Proceedings of the National Academy of Sciences of the United States of America. 1998; 95(24):14529-14534. doi: 10.1111/j.1749-6632.2001.tb05714.x. [PubMed: 9826734]

Desimone R. Visual attention mediated by biased competition in extrastriate visual cortex. Philosophical Transactions of the Royal Society of London Series B-Biological Sciences. 1998; 353(1373):1245-1255. doi: 10.1098/rstb.1998.0280.

Desimone R, Duncan J. Neural Mechanisms of selective visual-attention. Annual Review of Neuroscience. 1995; 18:193-222.

Detterman DK, Ellis NR. Determinants of induced amnesia in short-term memory. Journal of Experimental Psychology. 1972; 95(2) 308-\& doi: 10.1037/h0033629.

Doerksen S, Shimamura AP. Source memory enhancement for emotional words. Emotion. 2001; 1(1): 5-11. doi: 10.1037/1528-3542.1.1.5. [PubMed: 12894807]

Dolcos F, Kragel P, Wang LH, McCarthy G. Role of the inferior frontal cortex in coping with distracting emotions. Neuroreport. 2006; 17(15):1591-1594. doi: 10.1097/01.wnr. 0000236860.24081.be. [PubMed: 17001274]

Dolcos F, McCarthy G. Brain systems mediating cognitive interference by emotional distraction (Feb 15, pg 2072, 2006). Journal of Neuroscience. 2006; 26(10):2839-2839. doi: 10.1523/ JNEUROSCI.5042-05.2006.

Duncan J. EPS Mid-Career Award 2004 - Brain mechanisms of attention. Quarterly Journal of Experimental Psychology. 2006; 59(1):2-27. doi: 10.1080/17470210500260674.

Easterbrook JA. The effect of emotion on cue utilization and the organization of behavior. Psychological Review. 1959; 66(3):183-201. doi: 10.1037/h0047707. [PubMed: 13658305] 
Ellis NR, Detterman DK, Runcie D, McCarver RB, Craig EM. Amnesic effects in short-term memory. Journal of Experimental Psychology. 1971; 89(2) 357-\& doi: 10.1037/h0031192.

Erdelyi MH, Blumenth DG. Cognitive masking in rapid sequential processing - effect of an emotional picture on preceding and succeeding pictures. Memory \& Cognition. 1973; 1(3):201-204.

Fecteau JH, Munoz DP. Salience, relevance, and firing: a priority map for target selection. Trends in Cognitive Sciences. 2006; 10(8):382-390. doi: 10.1016/j.tics.2006.06.011. [PubMed: 16843702]

Gable PA, Harmon-Jones E. The blues broaden, but the nasty narrows: Attentional consequences of negative affects low and high in motivational intensity. Psychological Science. 2010a; 21(2):211215. doi: 10.1177/0956797609359622. [PubMed: 20424047]

Gable PA, Harmon-Jones E. The effect of low versus high approach-motivated positive affect on memory for peripherally versus centrally presented information. Emotion. 2010b; 10(4):599-603. doi: 10.1037/a0018426. [PubMed: 20677877]

Gazzaley A, Cooney JW, McEvoy K, Knight RT, D'Esposito M. Top-down enhancement and suppression of the magnitude and speed of neural activity. Journal of Cognitive Neuroscience. 2005; 17(3):507-517. doi: 10.1162/0898929053279522. [PubMed: 15814009]

Guillet R, Arndt J. Taboo words: The effect of emotion on memory for peripheral information. Memory \& Cognition. 2009; 37(6):866-879. doi: 10.3758/mc.37.6.866.

Hadley CB, MacKay DG. Does emotion help or hinder immediate memory? Arousal versus prioritybinding mechanisms. Journal of Experimental Psychology-Learning Memory and Cognition. 2006; 32(1):79-88. doi: 10.1037/0278-7393.32.1.79.

Hamann SB, Ely TD, Hoffman JM, Kilts CD. Ecstasy and agony: Activation of the human amygdala in positive and negative emotion. Psychological Science. 2002; 13(2):135-141. doi: 10.1111/1467-9280.00425. [PubMed: 11933997]

Hampshire A, Duncan J, Owen AM. Selective tuning of the blood oxygenation level-dependent response during simple target detection dissociates human frontoparietal subregions. Journal of Neuroscience. 2007; 27(23):6219-6223. doi: 10.1523/jneurosci.0851-07.2007. [PubMed: 17553994]

Henckens M, Hermans EJ, Pu ZW, Joels M, Fernandez GN. Stressed Memories: How Acute Stress Affects Memory Formation in Humans. Journal of Neuroscience. 2009; 29(32):10111-10119. doi: 10.1523/jneurosci.1184-09.2009. [PubMed: 19675245]

Hockey GRJ. Effect of loud noise on attentional selectivity. Quarterly Journal of Experimental Psychology. 1970a; 22 28-\& doi: 10.1080/14640747008401898.

Hockey GRJ. Signal probability and spatial location as possible bases for increased selectivity in noise. Quarterly Journal of Experimental Psychology. 1970b; 22 37-\& doi: 10.1080/14640747008401899.

Hockey GRJ, Hamilton P. Arousal and information selection in short-term memory. Nature. 1970; 226(5248) 866-\& doi: 10.1038/226866a0.

Hon N, Epstein RA, Owen AM, Duncan J. Frontoparietal activity with minimal decision and control. Journal of Neuroscience. 2006; 26(38):9805-9809. doi: 10.1523/jneurosci.3165-06.2006. [PubMed: 16988051]

Hung J, Driver J, Walsh V. Visual selection and posterior parietal cortex: Effects of repetitive transcranial magnetic stimulation on partial report analyzed by Bundesen's theory of visual attention. Journal of Neuroscience. 2005; 25(42):9602-9612. doi: 10.1526/jneurosci. 0879-05.2005. [PubMed: 16237165]

Hurlemann R, Hawellek B, Matusch A, Kolsch H, Wollersen H, Madea B, et al. Noradrenergic modulation of emotion-induced forgetting and remembering. Journal of Neuroscience. 2005; 25(27):6343-6349. doi: 10.1523/JNEUROSCI.0228-05.2005. [PubMed: 16000624]

Itti L, Baldi P. Bayesian surprise attracts human attention. Vision Research. 2009; 49(10):1295-1306. doi: 10.1016/j.visres.2008.09.007. [PubMed: 18834898]

Itti L, Koch C. A saliency-based search mechanism for overt and covert shifts of visual attention. Vision Research. 2000; 40(10-12):1489-1506. doi: 10.1016/S0042-6989(99)00163-7. [PubMed: 10788654]

James, W. The principles of psychology. New York: Dover; 1890. 
Johnson MR, Johnson MK. Top-down enhancement and suppression of activity in category-selective extrastriate cortex from an act of reflective attention. Journal of Cognitive Neuroscience. 2009a; 21(12):2320-2327. doi: 10.1162/jocn.2008.21183. [PubMed: 19199413]

Johnson, MR.; Johnson, MK. Toward characterizing the neural correlates of component processes of cognition. In: Roesler, F.; Ranganath, C.; Roeder, B.; Kluwe, RH., editors. Neuroimaging and psychological theories of human memory. New York: Oxford University Press; 2009b. p. 169-194.

Jonides J, Nee DE. Brain mechanisms of proactive interference in working memory. Neuroscience. 2006; 139(1):181-193. doi: 10.1016/j.neuroscience.2005.06.042. [PubMed: 16337090]

Jurado-Berbel P, Costa-Miserachs D, Torras-Garcia M, Coll-Andreu M, Portell-Cortes I. Standard object recognition memory and "what" and "where" components: Improvement by post-training epinephrine in highly habituated rats. Behavioural Brain Research. 2010; 207(1):44-50. doi: 10.1016/j.bbr.2009.09.036. [PubMed: 19788899]

Kastner S, De Weerd P, Desimone R, Ungerleider LC. Mechanisms of directed attention in the human extrastriate cortex as revealed by functional MRI. Science. 1998; 282(5386):108-111. doi: 10.1126/science.282.5386.108. [PubMed: 9756472]

Kastner S, Ungerleider LG. The neural basis of biased competition in human visual cortex. Neuropsychologia. 2001; 39(12):1263-1276. doi: 10.1016/S0028-3932(01)00116-6. [PubMed: 11566310]

Kayser C, Petkov CI, Lippert M, Logothetis NK. Mechanisms for allocating auditory attention: An auditory saliency map. Current Biology. 2005; 15(21):1943-1947. doi: 10.1016/j.cub.2005.09.040. [PubMed: 16271872]

Keil A, Ihssen N. Identification facilitation for emotionally arousing verbs during the attentional blink. Emotion. 2004; 4(1):23-35. doi: 10.1037/1528-3542.4.1.23. [PubMed: 15053724]

Kensinger EA. Negative emotion enhances memory accuracy: Behavioral and neuroimaging evidence. Current Directions in Psychological Science. 2007; 16(4):213-218. doi: 10.1111/j. 1467-8721.2007.00506.x.

Kensinger EA. Remembering the details: Effects of emotion. Emotion Review. 2009; 1:99-113. doi: 10.1177/1754073908100432. [PubMed: 19421427]

Kensinger EA, Corkin S. Memory enhancement for emotional words: Are emotional words more vividly remembered than neutral words? Memory \& Cognition. 2003; 31(8):1169-1180. doi: 10.1037/1528-3542.3.4.378.

Kensinger EA, Garoff-Eaton RJ, Schacter DL. Memory for specific visual details can be enhanced by negative arousing content. Journal of Memory and Language. 2006; 54(1):99-112. doi: 10.1016/ j.jml.2005.05.005.

Kensinger EA, Garoff-Eaton RJ, Schacter DL. Effects of emotion on memory specificity: Memory trade-offs elicited by negative visually arousing stimuli. Journal of Memory and Language. 2007; 56(4):575-591. doi: 10.1016/j.jml.2006.05.004.

Kensinger EA, Gutchess AH, Schacter DL. Effects of aging and encoding instructions on emotioninduced memory trade-offs. Psychology and Aging. 2007; 22(4):781-795. doi: 10.1037/0882-7974.22.4.781. [PubMed: 18179297]

Kensinger EA, Schacter DL. Neural processes supporting young and older adults' emotional memories. Journal of Cognitive Neuroscience. 2008; 20(7):1161-1173. doi: 10.1162/jocn.2008.20080. [PubMed: 18284340]

Kim HS, Baron RS. Excercise and the illusory correlation - does arousal heighten stereotypic processing. Journal of Experimental Social Psychology. 1988; 24(4):366-380. doi: 10.1016/0022-1031(88)90026-1.

Knight M, Mather M. Reconciling findings of emotion-induced memory enhancement and impairment of preceding items. Emotion. 2009; 9(6):763-781. doi: 10.1037/a0017281. [PubMed: 20001121]

Knight M, Seymour TL, Gaunt JT, Baker C, Nesmith K, Mather M. Aging and goal-directed emotional attention: Distraction reverses emotional biases. Emotion. 2007; 7(4):705-714. doi: 10.1037/1528-3542.7.4.705. [PubMed: 18039037]

LaBar KS, Cabeza R. Cognitive neuroscience of emotional memory. Nature Reviews Neuroscience. 2006; 7(1):54-64. 
LaBar KS, Mesulam MM, Gitelman DR, Weintraub S. Emotional curiousity: Modulation of visuospatial attention by arousal is preserved in aging and early-stage Alzheimer's disease. Neuropsychologia. 2000; 38:1734-1740. doi: 10.1016/S0028-3932(00)00077-4. [PubMed: 11099731]

Laney C, Campbell HV, Heuer F, Reisberg D. Memory for thematically arousing events. Memory \& Cognition. 2004; 32(7):1149-1159.

Laretzaki G, Plainis S, Argyropoulos S, Pallikaris IG, Bitsios P. Threat and anxiety affect visual contrast perception. Journal of Psychopharmacology. 2010; 24(5):667-675. doi: 10.1177/0269881108098823. [PubMed: 19010976]

Lee KY, Lee TH, Yoon SJ, Cho YS, Choi JS, Kim HT. Neural correlates of top-down processing in emotion perception: An ERP study of emotional faces in white noise versus noise-alone stimuli. Brain Research. 2010; 1337:56-63. doi: 10.1016/j.brainres.2010.03.094. [PubMed: 20381474]

Levine LJ, Edelstein RS. Emotion and memory narrowing: A review and goal-relevance approach. Cognition \& Emotion. 2009; 23(5):833-875. doi: 10.1080/02699930902738863.

Lim SL, Padmala S, Pessoa L. Segregating the significant from the mundane on a moment-to-moment basis via direct and indirect amygdala contributions. Proceedings of the National Academy of Sciences of the United States of America. 2009; 106(39):16841-16846. doi: 10.1073/pnas. 0904551106. [PubMed: 19805383]

Liu DLJ, Graham S, Zorawski M. Enhanced selective memory consolidation following post-learning pleasant and aversive arousal. Neurobiology of Learning and Memory. 2008; 89(1):36-46. doi: 10.1016/j.nlm.2007.09.001. [PubMed: 17951081]

Livingstone M, Hubel D. Segregation of form, color, movement, and depth - anatomy, physiology, and perception. Science. 1988; 240(4853):740-749. doi: 10.1126/science.3283936. [PubMed: 3283936]

Loftus EF, Loftus GR, Messo J. Some facts about weapon focus. Law and Human Behavior. 1987; 11(1):55-62. doi: 10.1007/BF01044839.

MacKay DG, Ahmetzanov MV. Emotion, memory, and attention in the taboo Stroop paradigm: An experimental analogue of flashbulb memories. Psychological Science. 2005; 16:25-32. [PubMed: 15660848]

MacKay DG, Shafto M, Taylor JK, Marian DE, Abrams L, Dyer JR. Relations between emotion, memory, and attention: Evidence from taboo Stroop, lexical decision, and immediate memory tasks. Memory \& Cognition. 2004; 32(3):474-488.

Maheu FS, Joober R, Beaulieu S, Lupien SJ. Differential effects of adrenergic and corticosteroid hormonal systems on human short- and long-term declarative memory for emotionally arousing material. Behavioral Neuroscience. 2004; 118(2):420-428. doi: 10.1177/0735-7044.118.2.420. [PubMed: 15113269]

Mather M. Emotional arousal and memory binding an object-based framework. Perspectives on Psychological Science. 2007; 2(1):33-52. doi: 10.1111/j.1745-6916.2007.00028.x.

Mather M, Canli T, English T, Whitfield SL, Wais P, Ochsner KN, et al. Amygdala responses to emotionally valenced stimuli in older and younger adults. Psychological Science. 2004; 15:259_ 263. [PubMed: 15043644]

Mather M, Gorlick MA, Nesmith K. The limits of arousal's memory-impairing effects on nearby information. American Journal of Psychology. 2009; 122(3):349-369. [PubMed: 19827704]

Mather M, Johnson MK. Affective review and schema reliance in memory in older and younger adults. American Journal of Psychology. 2003; 116(2):169-189. doi: 10.2307/1423576. [PubMed: 12762174]

Mather M, Johnson MK, De Leonardis DM. Stereotype reliance in source monitoring: Age differences and neuropsychological test correlates. Cognitive Neuropsychology. 1999; 16(3-5):437-458. doi: 10.1080/026432999380870.

Mather M, Mitchell KJ, Raye CL, Novak DL, Greene EJ, Johnson MK. Emotional arousal can impair feature binding in working memory. Journal of Cognitive Neuroscience. 2006; 18(4):614-625. doi: 10.1162/jocn.2006.18.4.614. [PubMed: 16768364]

Mather M, Nesmith K. Arousal-enhanced location memory for pictures. Journal of Memory and Language. 2008; 58(2):449-464. doi: 10.1016/j.jml.2007.01.004. [PubMed: 19190722] 
Mather M, Sutherland MR. Disentangling the effects of arousal and valence on memory for intrinsic details. Emotion Review. 2009; 1:118-119. doi: 10.1177/1754073908100435.

McGaugh JL. The amygdala modulates the consolidation of memories of emotionally arousing experiences. Annual Review of Neuroscience. 2004; 27:1-28.

Mickley KP, Kensinger EA. Emotional valence influences the neural correlates associated with remembering and knowing. Cognitive Affective \& Behavioral Neuroscience. 2008; 8(2):143152. doi: 10.3758/cabn.8.2.143.

Miller EK, Cohen JD. An integrative theory of prefrontal cortex function. Annual Review of Neuroscience. 2001; 24:167-202.

Mitchell DGV, Luo Q, Mondillo K, Vythilingam M, Finger EC, Blair RJR. The interference of operant task performance by emotional distracters: An antagonistic relationship between the amygdala and frontoparietal cortices. NeuroImage. 2008; 40(2):859-868. doi: 10.1016/j.neuroimage. 2007.08.002. [PubMed: 18234519]

Mitchell JF, Stoner GR, Reynolds JH. Object-based attention determines dominance in binocular rivalry. Nature. 2004; 429(6990):410-413. doi: 10.1038/nature02584. [PubMed: 15164062]

Mitchell KJ, Johnson MR, Higgins JA, Johnson MK. Age differences in brain activity during perceptual versus reflective attention. Neuroreport. 2010; 21(4):293-297. doi: 10.1097/WNR. 0b013e32833730d6. [PubMed: 20125054]

Mitchell KJ, Mather M, Johnson MK, Raye CL, Greene EJ. A functional magnetic resonance imaging investigation of short-term source and item memory for negative pictures. Neuroreport. 2006; 17(14):1543-1547. doi: 10.1097/01.wnr.0000234743.50442.e5. [PubMed: 16957605]

Miu AC, Heilman RM, Opre A, Miclea M. Emotion-induced retrograde amnesia and trait anxiety. Journal of Experimental Psychology-Learning Memory and Cognition. 2005; 31(6):1250-1257. doi: 10.1037/0278-7393.31.6.1250.

Morelli F, Burton PA. The impact of induced stress upon selective attention in multiple object tracking. Military Psychology. 2009; 21(1):81-97. doi: 10.1080/08995600802565769.

Murty VP, Ritchey M, Adcock RA, LaBar KS. fMRI studies of successful emotional memory encoding A quantitative meta-analysis. Neuropsychologia. 48(12):3459-3469. doi: 10.1016/ j.neuropsychologia.2010.07.030. [PubMed: 20688087]

Nashiro K, Mather M. How arousal affects younger and older adults' memory binding. Experimental Aging Research. (in press).

Nielson KA, Powless M. Positive and negative sources of emotional arousal enhance long-term wordlist retention when induced as long as $30 \mathrm{~min}$ after learning. Neurobiology of Learning and Memory. 2007; 88(1):40-47. doi: 10.1016/j.nlm.2007.03.005. [PubMed: 17467310]

Nielson KA, Yee D, Erickson KI. Memory enhancement by a semantically unrelated emotional arousal source induced after learning. Neurobiology of Learning and Memory. 2005; 84(1):49-56. doi: 10.1016/j.nlm.2005.04.001. [PubMed: 15890540]

Nobata T, Hakoda Y, Ninose Y. The functional field of view becomes narrower while viewing negative emotional stimuli. Cognition \& Emotion. 2009 doi: 10.1080/02699930902955954.

Nothdurft HC. Salience from feature contrast: additivity across dimensions. Vision Research. 2000; 40(10-12):1183-1201. doi: 10.1016/S0042-6989(00)00031-6. [PubMed: 10788635]

Nummenmaa L, Hyona J, Calvo MG. Eye movement assessment of selective attentional capture by emotional pictures. Emotion. 2006; 6(2):257-268. doi: 10.1037/1528-3542.6.2.257. [PubMed: 16768558]

O'Craven KM, Downing PE, Kanwisher N. fMRI evidence for objects as the units of attentional selection. Nature. 1999; 401(6753):584-587. doi: 10.1038/44134. [PubMed: 10524624]

O'Doherty J, Rolls ET, Francis S, Bowtell R, McGlone F. Representation of pleasant and aversive taste in the human brain. Journal of Neurophysiology. 2001; 85(3):1315-1321. [PubMed: 11248000]

Padmala S, Pessoa L. Affective learning enhances visual detection and responses in primary visual cortex. Journal of Neuroscience. 2008; 28(24):6202-6210. doi: 10.1523/jneurosci.1233-08.2008. [PubMed: 18550762]

Payne JD, Kensinger EA. Sleep's role in the consolidation of emotional episodic memories. Current Directions in Psychological Science. 2010; 19(5):290-295. doi: 10.1177/0963721410383978. 
Payne JD, Nadel L, Allen JJB, Thomas KGF, Jacobs WJ. The effects of experimentally induced stress on false recognition. Memory. 2002; 10(1):1-6. [PubMed: 11747571]

Phelps EA. Human emotion and memory: Interactions of the amygdala and hippocampal complex. Current Opinion in Neurobiology. 2004; 14(2):198-202. [PubMed: 15082325]

Phelps EA, Ling S, Carrasco M. Emotion facilitates perception and potentiates the perceptual benefits of attention. Psychological Science. 2006; 17(4):292-299. doi: 10.1111/j. 1467-9280.2006.01701.x. [PubMed: 16623685]

Posner MI, Snyder CRR, Davidson BJ. Attention and the detection of signals. Journal of Experimental Psychology-General. 1980; 109(2):160-174. doi: 10.1037/0096-3445.109.2.160.

Ranganath C, Rainer G. Neural mechanisms for detecting and remembering novel events. Nature Reviews Neuroscience. 2003; 4(3):193-202. doi: 10.1038/nrn1052.

Reddy L, Kanwisher NG, VanRullen R. Attention and biased competition in multi-voxel object representations. Proceedings of the National Academy of Sciences of the United States of America. 2009; 106(50):21447-21452. doi: 10.1073/pnas.0907330106. [PubMed: 19955434]

Roozendaal B, Castello NA, Vedana G, Barsegyan A, McGaugh JL. Noradrenergic activation of the basolateral amygdala modulates consolidation of object recognition memory. Neurobiology of Learning and Memory. 2008; 90(3):576-579. doi: 10.1016/j.nlm.2008.06.010. [PubMed: 18657626]

Rosler A, Ulrich C, Billino J, Sterzer P, Weidauer S, Bernhardt T, et al. Effects of arousing emotional scenes on the distribution of visuospatial attention: changes with aging and early subcortical vascular dementia. Journal of the Neurological Sciences. 2005; 229:109-116. doi: 10.1016/j.jns. 2004.11.007. [PubMed: 15760628]

Rowe G, Hirsh JB, Anderson AK. Positive affect increases the breadth of attentional selection. Proceedings of the National Academy of Sciences of the United States of America. 2007; 104(1): 383-388. doi: 10.1073/pnas.0605198104. [PubMed: 17182749]

Runcie D, Obannon RM. Independence of induced amnesia and emotional response. American Journal of Psychology. 1977; 90(1):55-61. doi: 10.2307/1421640. [PubMed: 871179]

Sabatinelli D, Flaisch T, Bradley MM, Fitzsimmons JR, Lang PJ. Affective picture perception: gender differences in visual cortex? Neuroreport. 2004; 15(7):1109-1112. doi: 10.1097/01.wnr. 0000126558.41468.3d. [PubMed: 15129155]

Sakaki M, Gorlick MA, Mather M. Inhibitory effects of emotion on subsequent cognitive processing: Negative emotion impairs semantic processing but not perceptual processing of subsequent stimuli. (under review).

Sander D, Grafman J, Zalla T. The human amygdala: an evolved system for relevance detection. Reviews in the Neurosciences. 2003; 14(4):303-316. [PubMed: 14640318]

Schmidt SR. Outstanding memories: The positive and negative effects of nudes on memory. Journal of Experimental Psychology-Learning Memory and Cognition. 2002; 28(2):353-361. doi: 10.1037//0278-7393.28.2.353.

Schmitz TW, De Rosa E, Anderson AK. Opposing influences of affective state valence on visual cortical encoding. Journal of Neuroscience. 2009; 29(22):7199-7207. doi: 10.1523/jneurosci. 5387-08.2009. [PubMed: 19494142]

Scholl BJ. Objects and attention: the state of the art. Cognition. 2001; 80(1-2):1-46. [PubMed: 11245838]

Schupp, HT.; Flaisch, T.; Stockburger, J.; Junghofer, M. Emotion and attention: event-related brain potential studies. In: Anders; Ende; Junghofer; Kissler \& Wildgruber, editors. Progress in Brain Research. Vol. Vol. 156. 2006. p. 31-51.

Schupp HT, Stockburger J, Codispoti M, Junghofer M, Weike AI, Hamm AO. Selective visual attention to emotion. Journal of Neuroscience. 2007; 27(5):1082-1089. doi: 10.1523/jneurosci. 3223-06.2007. [PubMed: 17267562]

Segal SK, Cahill L. Endogenous noradrenergic activation and memory for emotional material in men and women. Psychoneuroendocrinology. 2009; 34(9):1263-1271. doi: 10.1016/j.psyneuen. 2009.04.020. [PubMed: 19505766]

Sheth BR, Pham T. How emotional arousal and valence influence access to awareness. Vision Research. 2008; 48(23-24):2415-2424. doi: 10.1016/j.visres.2008.07.013. [PubMed: 18694777] 
Smeets T, Otgaar H, Candel I, Wolf OT. True or false? Memory is differentially affected by stressinduced cortisol elevations and sympathetic activity at consolidation and retrieval. Psychoneuroendocrinology. 2008; 33(10):1378-1386. doi: 10.1016/j.psyneuen.2008.07.009. [PubMed: 18790572]

Smith AP. The effects of noise and task priority on recall of order and location. Acta Psychologica. 1982; 51(3):245-255. doi: 10.1016/0001-6918(82)90037-3. [PubMed: 7158395]

Steblay NM. A metaanalytic review of the weapon focus effect. Law and Human Behavior. 1992; 16(4):413-424. doi: 10.1007/BF02352267.

Storbeck J, Clore GL. The affective regulation of cognitive priming. Emotion. 2008; 8(2):208-215. doi: 10.1037/1528-3542.8.2.208. [PubMed: 18410195]

Strange BA, Hurlemann R, Dolan RJ. An emotion-induced retrograde amnesia in humans is amygdalaand beta-adrenergic-dependent. Proceedings of the National Academy of Sciences of the United States of America. 2003; 100(23):13626-13631. doi: 10.1073/pnas.1635116100. [PubMed: 14595032]

Sutherland MR, Mather M. Emotional arousal increases the impact of bottom-up salience in visual attention. (in preparation).

Taylor SF, Liberzon I, Koeppe RA. The effect of graded aversive stimuli on limbic and visual activation. Neuropsychologia. 2000; 38(10):1415-1425. doi: 10.1016/S0028-3932(00)00032-4. [PubMed: 10869585]

Treisman A. Solutions to the binding problem: Progress through controversy and convergence. Neuron. 1999; 24(1):105-110. doi: 10.1016/S0896-6273(00)80826-0. [PubMed: 10677031]

Valdes-Sosa M, Cobo A, Pinilla T. Attention to object files defined by transparent motion. Journal of Experimental Psychology-Human Perception and Performance. 2000; 26(2):488-505. doi: 10.1037//0096-1523.26.2.488. [PubMed: 10811159]

Vuilleumier P, Armony JL, Driver J, Dolan RJ. Effects of attention and emotion on face processing in the human brain: An event-related fMRI study. Neuron. 2001; 30(3):829-841. doi: 10.1016/ S0896-6273(01)00328-2. [PubMed: 11430815]

Walther DB, Koch C. Attention in hierarchical models of object recognition. Computational Neuroscience: Theoretical Insights into Brain Function. 2007; Vol. 165:57-78.

Waring JD, Kensinger EA. Effects of emotional valence and arousal upon memory tradeoffs with aging. Psychology and Aging. 2009; 24(2):412-422. doi: 10.1037/a0015526. [PubMed: 19485658]

Zald DH, Pardo JV. The neural correlates of aversive auditory stimulation. NeuroImage. 2002; 16(3): 746-753. doi: 10.1006/nimg.2002.1115. [PubMed: 12169258]

Zeelenberg R, Bocanegra BR. Auditory emotional cues enhance visual perception. Cognition. 2010; 115(1):202-206. doi: 10.1016/j.cognition.2009.12.004. [PubMed: 20096407]

\section{Acknowledgments}

This work was supported by National Institute on Aging grants R01 AG025340, R01 AG038043 and K02 AG032309.

We thank Laurent Itti, Marcia Johnson, Marisa Knight, Noah Mercer and Karen J. Mitchell for comments on a previous version of this paper. 


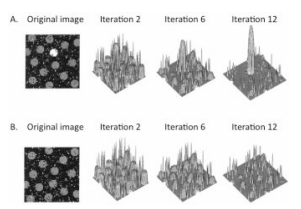

Figure 1.

Output from Itti and Koch's (2000) computational model to derive a saliency map from feature contrast. In $(A)$, one strongly activated location is surrounded by weaker ones. Iterative spatial competition leads this location to gain further strength while suppressing surrounding regions. In $(B)$, numerous strongly activated locations inhibit each other, leading to suppression of all locations. Figure adapted from Itti and Koch (2000). 
A.
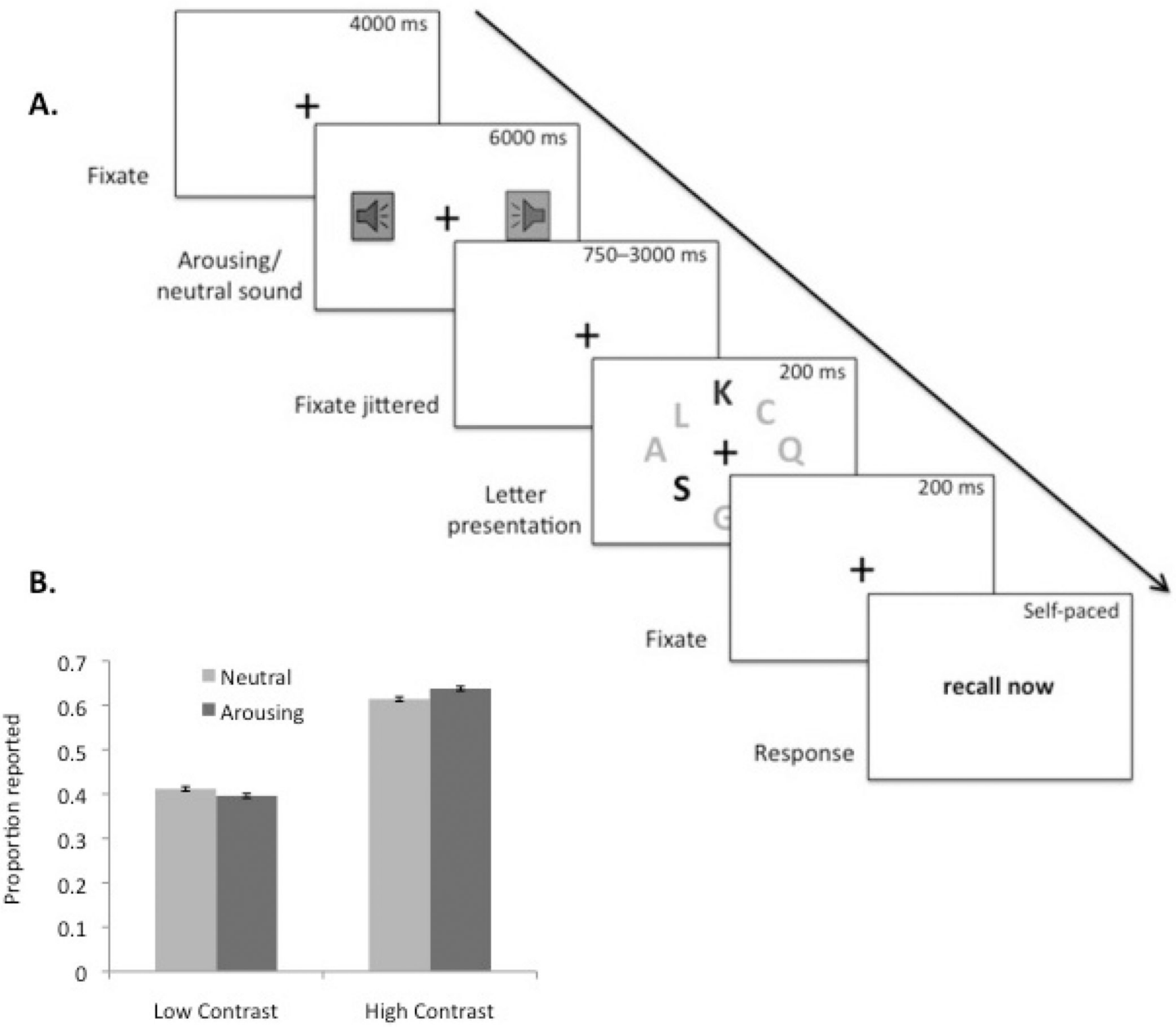

Figure 2.

(A) The sequence for each trial in Sutherland and Mather (in preparation); (B) Arousing sounds increased the proportion of dark letters reported and decreased the proportion of light letters reported. 


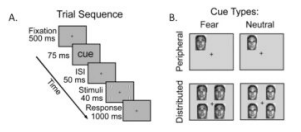

Figure 3.

(A) Trial sequence from Phelps et al., (2006). Participants indicated whether one of the four gratings was tilted or none were tilted. $(B)$ A preceding cue varied in its spatial location and in whether it was a fearful or neutral face. Figure adapted from Phelps et al., (2006). 

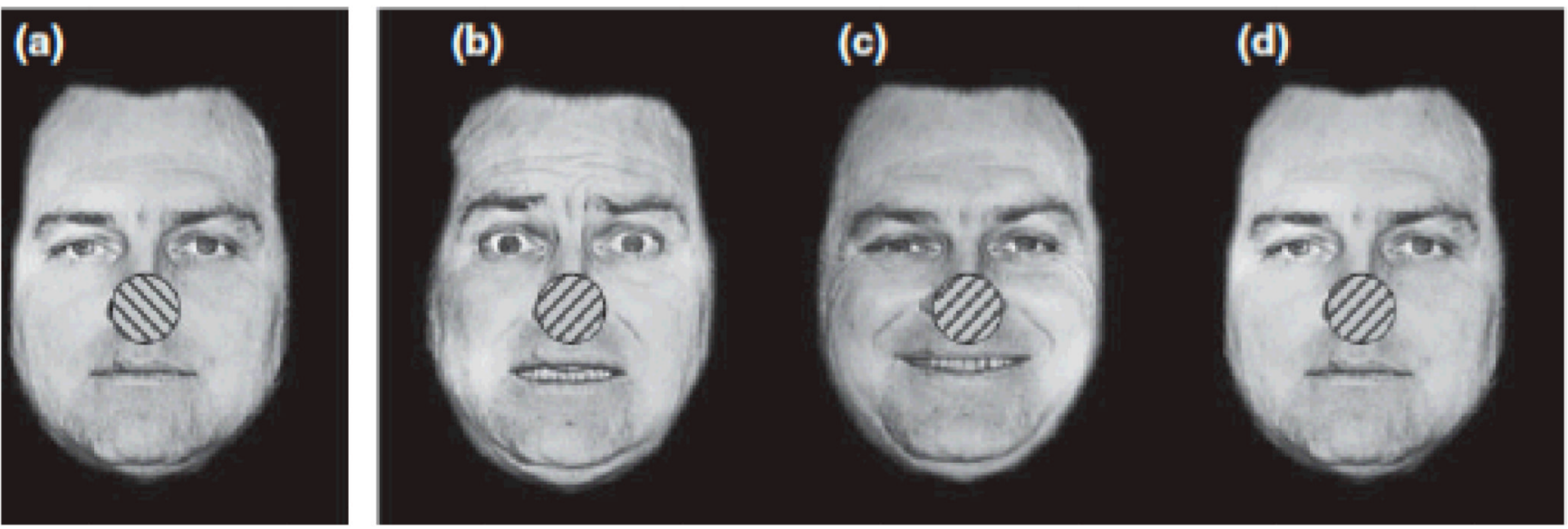

Figure 4.

Example stimuli used in Bannerman et al. (2008). Stimulus (a) was presented to one eye while stimulus $(b),(c)$ or $(d)$ was presented to the other eye. 
Stimuli

A.

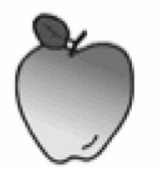

Figure 5.

Consolidation

Long-term

memory

No arousal

High priority Low priority
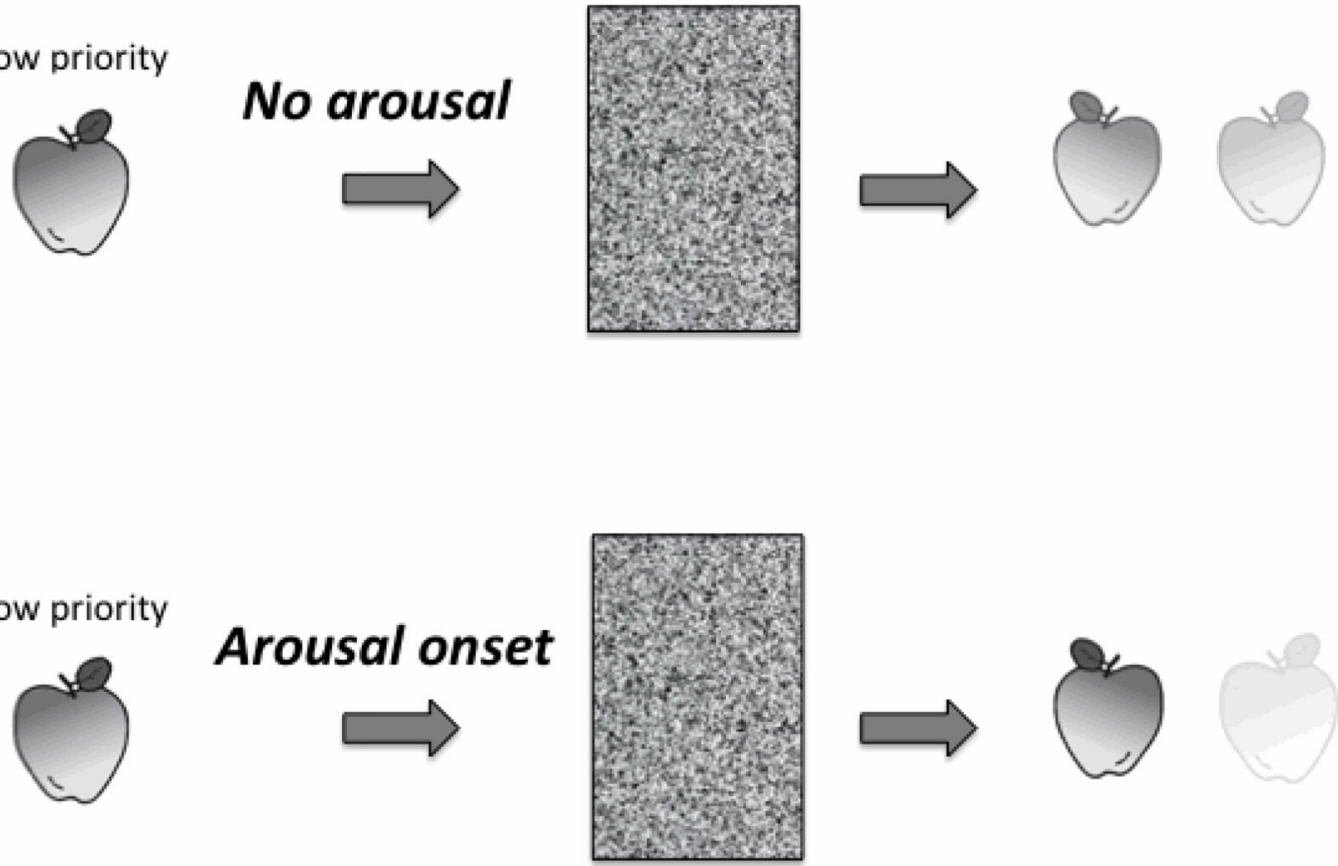

A schematic of how arousal-biased competition influences memory consolidation. (A) In an initial low-arousal encounter with two apples, one has higher priority than the other for either bottom-up or top-down reasons. After the passage of time and memory consolidation, memory representations for both apples have faded, but the initially higher priority apple has a stronger representation that is more easily and vividly retrieved than that of the lower priority apple. (B) Experiencing arousal while processing two stimuli in competition with each other for mental resources leads to even more enhancement in memory consolidation for the "winner" and impairment for the "loser," creating a "winner-take-more" effect in memory consolidation. 
Table 1

Some prominent characterizations of how arousal affects memory, with related findings; see text for how arousal-biased competition accounts for consistent and inconsistent findings.

\begin{tabular}{|c|c|c|}
\hline Arousal Effect & Finding(s) Illustrating the Effect & Inconsistent Finding(s) \\
\hline $\begin{array}{l}\text { 1. Arousal leads to } \\
\text { memory narrowing }\end{array}$ & $\begin{array}{l}\text { Emotional arousal enhances memory for central } \\
\text { details at the cost of peripheral details. This has } \\
\text { been interpreted as evidence that arousal causes } \\
\text { memory narrowing (Burke, Heuer, \& Reisberg, } \\
\text { 1992; Christianson, et al., 1991). A related } \\
\text { phenomena is the weapon-focus effect, in which } \\
\text { people remember the weapon when witnessing a } \\
\text { real or simulated crime, but forget other scene } \\
\text { details (Steblay, 1992). }\end{array}$ & $\begin{array}{l}\text { Thematically induced emotion enhances memory for non- } \\
\text { central information (Laney, et al., 2004). Also, an arousing } \\
\text { picture shown in one location on the screen impairs memory } \\
\text { for background information more than for spatially peripheral } \\
\text { but foreground information (Mather, et al., 2009). }\end{array}$ \\
\hline $\begin{array}{l}\text { 2. Emotional arousal } \\
\text { enhances memory } \\
\text { for gist but not } \\
\text { detail }\end{array}$ & $\begin{array}{l}\text { Interspersing emotional slides throughout a slide } \\
\text { show rather than neutral slides increases the degree } \\
\text { to which participants recall the gist rather than the } \\
\text { details of certain target (non-manipulated) slides, } \\
\text { indicating that emotional arousal enhances memory } \\
\text { for the gist but not details of events (Adolphs, et } \\
\text { al., 2005). }\end{array}$ & $\begin{array}{l}\text { Memory is better for the specific details of emotional objects } \\
\text { than non-emotional objects (Kensinger, et al., 2006), and } \\
\text { whether emotion enhances or impairs memory for the gist and } \\
\text { details depends on how attention was directed during encoding } \\
\text { (Kensinger, Garoff-Eaton, et al., 2007). }\end{array}$ \\
\hline $\begin{array}{l}\text { 3. Arousal enhances } \\
\text { within-object } \\
\text { memory binding }\end{array}$ & $\begin{array}{l}\text { Emotional arousal enhances memory of intrinsic } \\
\text { features of an object but does not enhance memory } \\
\text { for associations between items (Kensinger, 2009; } \\
\text { Mather, 2007). }\end{array}$ & $\begin{array}{l}\text { Participants asked to learn word pairs and then given the first } \\
\text { word in the pair as a cue to retrieve the second word were } \\
\text { better at recalling neutral words paired with emotionally } \\
\text { arousing words (Guillet \& Arndt, 2009). }\end{array}$ \\
\hline $\begin{array}{l}\text { 4. Arousal creates } \\
\text { retrograde amnesia }\end{array}$ & $\begin{array}{l}\text { Arousing words or pictures can lead to retrograde } \\
\text { amnesia, in which preceding neutral words or } \\
\text { pictures are more likely to be forgotten (Knight \& } \\
\text { Mather, 2009; Strange, et al., 2003) }\end{array}$ & $\begin{array}{l}\text { Arousing pictures can lead to retrograde enhancement, in which } \\
\text { preceding pictures are more likely to be recalled (Anderson, et } \\
\text { al., 2006; Knight \& Mather, 2009). }\end{array}$ \\
\hline $\begin{array}{l}\text { 5. Arousal enhances } \\
\text { consolidation for } \\
\text { emotional items }\end{array}$ & $\begin{array}{l}\text { Post-encoding arousal enhances memory for } \\
\text { emotional stimuli more than for neutral stimuli, } \\
\text { indicating that arousal enhances memory } \\
\text { consolidation of emotional but not neutral } \\
\text { information (Buchanan \& Lovallo, 2001; Cahill, et } \\
\text { al., 2003). }\end{array}$ & $\begin{array}{l}\text { Arousal experienced after exposure to neutral information can } \\
\text { enhance memory for that neutral information when tested a } \\
\text { couple of days or a week later (Abercrombie, Kalin, Thurow, } \\
\text { Rosenkranz, \& Davidson, 2003; Anderson, et al., 2006; } \\
\text { Andreano \& Cahill, 2006; Knight \& Mather, 2009; Nielson \& } \\
\text { Powless, 2007; Nielson, et al., 2005; see also Maheu, et al., } \\
\text { 2004). }\end{array}$ \\
\hline
\end{tabular}

